\title{
Aproximación para establecer y evaluar la relevancia clínica de las interacciones medicamentosas en el tratamiento de pacientes infectados con virus de hepatitis C genotipo 1 - Revisión estructurada
}

\section{A Structured Review of Approaches for Establishing and Evaluating Clinical Relevance of Drug Interactions in Patients with Hepatitis C Virus Genotype 1}

\author{
Grupo de promoción y prevención farmacéutica \\ (P\&PF), Universidad de Antioquia. Medellín, \\ Colombia. \\ 2 Químico farmacéutico. Departamento de Farmacia, \\ Universidad de Antioquia UdeA. Medellín, Colombia.

Daniel Pino-Marín, ${ }^{1,2}$ Newar Giraldo, PhD, ,,2 Pedro Amariles, PhD. ${ }^{1,2}$

\begin{abstract}
Resumen
Objetivo: establecer y evaluarla relevancia clínica de interacciones medicamentosas en el tratamiento de pacientes con hepatitis C genotipo 1. Método: se realizó una búsqueda en PubMed/MedLine de artículos publicados en inglés y en español, desde el diciembre de 2004 a diciembre de 2014, utilizando los términos Mesh: Hepatitis C AND drug interactions OR herb-drug interactions OR food-drug interactions, de estudios realizados en humanos. Además, la búsqueda se complementó con la revisión, en el mismo período, sobre interacciones de antiretrovirales y hepatitis $\mathrm{C}$ en humanos, utilizando los términos Mesh: (Anti-retroviral agents AND Hepatitis $C$ AND drug interactions OR herb-drug interactions OR food-drug interactions). La relevancia clínica de las interacciones medicamentosas se definió y evaluó con base a la probabilidad de ocurrencia y la gravedad de la interacción. Resultados: se identificaron 228 artículos, de los que se pudo acceder al texto completo en 212. De estos, 62 aportaban interacciones, lo que permitió identificar 128 parejas de IM, de las cuales $120(93,7 \%)$ fueron farmacocinéticas y $8(6,3 \%)$ farmacodinámicas. Por su parte, de estas 128 parejas, $2(1,6 \%)$ fueron valoradas de nivel 1: $110(53,7 \%)$ de nivel 2; $16(7,8 \%)$ de nivel 3; y $0(0 \%)$ de nivel 4. Además, se identificaron 78 parejas agrupadas como interacciones con evidencia de ausencia de relevancia clínica. Conclusiones: más del $90 \%$ de las interacciones medicamentosas de relevancia clínica son farmacocinéticas asociadas a cambios del metabolismo hepático, el telaprevir fue el medicamento con mayor número de interacciones.
\end{abstract}

\section{Palabras clave}

Interacciones medicamentosas, antirretrovirales, hepatitis C, boceprevir, telaprevir.

\begin{abstract}
Objective: Our objective was to establish and evaluate the clinical relevance of drug interactions in the treatment of patients with hepatitis $C$ genotype 1. Method: We searched for articles published in English and Spanish from December 2004 to December 2014 in PubMed/MedLine. We used the following Medical Subject Headings (MESH): Hepatitis $\mathrm{C}$ and drug interactions OR herb-drug interactions OR food-drug interactions studies performed in humans. We conducted an additional complementary search for articles published in the same period about interactions of anti-retroviral and hepatitis $\mathrm{C}$ in humans using the following MESH: (Antiretroviral agents AND Hepatitis $\mathrm{C}$ and drug interactions $\mathrm{OR}$ herb-drug interactions $\mathrm{OR}$ food -drug interactions). The clinical relevance of drug interactions was defined and evaluated based on the probability of occurrence and severity of interaction. Results: We identified 228 articles. Of these, it was possible to read the full text of 212. Of these, 62 contributed interactions which allowed us to identify 128 pairs of drug interactions, of which $120(93.7 \%)$ were pharmacokinetic and $8(6.3 \%)$ pharmacodynamic. Of these 128 pairs, two (1.6\%) were rated Level 1: $110(53.7 \%)$ were Level 2, $16(7.8 \%)$ were Level 3, and $0(0 \%)$ were Level 4 . In addition, 78 pairs were identified that were grouped as interactions with evidence of absence of clinical significance. Conclusions: More than $90 \%$ of clinically relevant drug interactions are pharmacokinetic interactions associated with hepatic metabolism. Telaprevir has the greatest number of interactions.
\end{abstract}

\section{Keywords}

Drug Interactions, Antiretrovirals, Hepatitis C, boceprevir, telaprevir. 


\section{INTRODUCCIÓN}

El virus de la hepatitis C (VHC) presenta mínimo 6 genotipos y unas 100 cepas diferentes, cuya prevalencia y respuesta al tratamiento varía geográficamente. De dichas variantes, el genotipo 1 es el responsable de la infección en América y Europa (1). La carga de RNA-VHC indetectable a las 24 semanas, después de finalizar el tratamiento o respuesta viral sostenida (RVS) es el parámetro utilizado para valorar la efectividad del tratamiento antiviral (2). Para el genotipo 1, el tratamiento previo se fundamentó en la utilización de interferón alfa pegilado (INF) y ribavirina (RIB), esquema con el que se alcanza una RVS del $40 \%$ a $50 \%$. Más recientemente, la utilización de nuevos fármacos, en especial inhibidores de proteasa sérica (IP) (telaprevir (TLV) y boceprevir (BOC), permite alcanzar respuestas entre el $60 \%$ al $75 \%$ en pacientes naive. Además, la duración del tratamiento pasó de 48 a 24-28 semanas (e incluso a 12), dependiendo del tipo de inhibidor de polimerasa o proteasa utilizado, al igual que del comportamiento de la respuesta virológica (1).

El tratamiento en pacientes infectados con el VHC, debido a la disponibilidad y utilización de este nuevo grupo de fármacos, podría asimilarse a lo sucedido con la terapia antirretroviral de gran actividad (TARGA) en los pacientes infectados con el virus de la inmunodeficiencia humana (VIH) (1). Como se sabe, la TARGA ha generado una disminución significativa en la mortalidad y morbilidad, pero a su vez se ha asociado con la aparición de reacciones adversas, problemas de adherencia y, especialmente, interacciones medicamentosas (IM).

En pacientes infectados con VIH, la coinfección con VHC es un hallazgo frecuente, debido especialmente a la similitud en la forma de contagio (sexual, parenteral o vertical) (3). Adicionalmente, la existencia del VHC condiciona el inicio precoz del tratamiento del VIH, al tiempo que el VIH agrava y acelera la progresión de la hepatitis, lo que genera un incremento de 2 a 8 veces en la carga viral del VHC, al igual que una mayor progresión de la infección y aparición de cirrosis $(4,5)$. Por tanto, en pacientes con VIH el tratamiento antiviral para el VHC es una situación que puede ser común en la práctica clínica y estar asociado a la presentación de IM relacionadas con el tratamiento farmacológico de ambas morbilidades. Estas interacciones se deben, en parte, a la capacidad de los antiretrovirales de inducir o inhibir el metabolismo hepático, o de generar interacciones farmacodinámicas o potenciar la lesión hepática (6). Por ello, las interacciones en pacientes con VHC son una situación común y de interés clínico que requiere ser profundizado. En este sentido, el objetivo del presente trabajo fue establecer y evaluar la relevancia clínica de las IM en pacientes infectados con virus de hepatitis $\mathrm{C}$ genotipo 1: a partir de una revisión estructurada, basándose en la gravedad y en la probabilidad de ocurrencia de la interacción.

\section{MÉTODO}

Se realizó una búsqueda en PubMed/MedLine de artículos publicados en inglés y español, desde el 1 de diciembre de 2004 hasta el 31 de diciembre de 2014, utilizando los términos Mesh: (Hepatitis C AND drug interactions OR herb-drug interactions OR food-drug interactions). Además, debido a la posibilidad de coinfección VHC y VIH, y a que en los últimos años, algunos antirretrovirales se han posicionado en el tratamiento de la hepatitis $\mathrm{C}$, caso del ritonavir como agente extensor o potenciador de algunos IP, la búsqueda se complementó con una revisión en el mismo período (diciembre de 2004 a diciembre de 2014) sobre interacciones de ARV en humanos y hepatitis $\mathrm{C}$, utilizando los siguientes términos Mesh: (Anti-retroviral agents AND Hepatitis C AND drug interactions OR herb-drug interactions OR food-drug interactions).

\section{Criterios de inclusión}

Solamente las revisiones sistemáticas, metaanálisis, estudios multicéntricos, ensayos clínicos aleatorizados controlados, estudios cuasi-experimentales (no aleatorizados), estudios observacionales, guías, cartas y reportes de caso; en humanos, lenguaje en español e inglés y con acceso a texto completo fueron seleccionados para la revisión. Los artículos de IM entre medicamentos usados en el tratamiento de la hepatitis $\mathrm{C}$ con otros medicamentos, $\mathrm{y}$ algunas de las referencias usadas en dichos trabajos, con el fin de ampliar el contexto o aumentar el soporte de los resultados, fueron incluidos.

\section{Criterios de exclusión}

Publicaciones con métodos in vitro o en animales, con fármacos en fase experimental y aquellos que no abordaron interacciones con medicamentos para el tratamiento de la hepatitis C.

\section{Métodos de revisión}

Los artículos incluidos fueron seleccionados por 3 investigadores de forma independiente. Para ello, se revisaron los títulos y resúmenes de todos los artículos identificados para decidir su elegibilidad. Los artículos seleccionados se analizaron conjuntamente y, por consenso, se definió su inclusión o no. 


\section{Medidas de resultado y valoración de la relevancia clínica de las interacciones}

La relevancia clínica de las IM se definió y evaluó utilizando la probabilidad de ocurrencia y la gravedad de la interacción $(7,8)$. La probabilidad de aparición de la interacción se estableció en 3 categorías (definida, probable o posible), a partir del tipo de estudio que documenta la interacción y que ha sido publicado en revistas con revisiones previas e indexadas.

- Definida: interacción documentada en metaanálisis, revisiones sistemáticas o ensayos clínicos aleatorizados o no aleatorizados.

- Probable: interacción documentada en estudios analíticos o por la descripción de 3 o más casos clínicos.

- Posible: interacciones documentadas por la descripción de menos de 3 casos o por recomendaciones de expertos.

Por su parte, la gravedad de la interacción se estableció en 3 categorías:

- Grave: la interacción puede causar daño o lesión al paciente; la consecuencia del resultado clínico negativo de la farmacoterapia puede causar o generar en el paciente la muerte, riesgo para la vida, hospitalización, una incapacidad permanente o significativa, anomalías congénitas o malformaciones al nacer, al igual que otros efectos que a juicio médico puedan comprometer la integridad del paciente y generar la necesidad de realizar una intervención quirúrgica para evitar la muerte, hospitalización o anomalías congénitas.

- Moderada: la interacción genera la necesidad de realizar un seguimiento del paciente. La consecuencia del resultado clínico negativo de la farmacoterapia puede causar una modificación (cambio o interrupción) de la farmacoterapia o el empleo de nuevos fármacos para tratar el problema relacionado con medicamentos o bien la prolongación de la hospitalización.

- Leve: la interacción no causa daño al paciente. La consecuencia del resultado negativo de la medicación no requiere la modificación (cambio o retiro) de la farmacoterapia o el empleo de nuevos fármacos para tratar el problema relacionado con los medicamentos ni prolonga la hospitalización del paciente.

A partir de las combinaciones posibles de gravedad y probabilidad de aparición, las interacciones pueden agruparse en 4 categorías:

- Nivel 1 (riesgo muy alto): resultante de la combinación de grave y definida, o grave y probable. La utilización simultánea de los medicamentos se considera contraindicada de forma absoluta.
- Nivel 2 (riesgo alto): resultante de la combinación de grave y posible; moderada y definida o moderada y probable. La utilización simultánea de los medicamentos requiere el ajuste de la pauta posológica, valorar signos y síntomas de efectividad y seguridad del tratamiento, idealmente de forma cuantitativa.

- Nivel 3 (riesgo medio): resultante de la combinación de moderada y posible; leve y definida, o leve y probable. La utilización simultánea de los medicamentos requiere el ajuste de la posología o valorar signos y síntomas de efectividad y seguridad del tratamiento, idealmente de forma cuantitativa.

- Nivel 4 (riesgo bajo): resultante de la combinación leve y posible. La interacción es de escaza relevancia clínica.

Adicionalmente, se elaboró un listado de parejas de medicamentos con evidencia de ausencia de interacciones clínicamente relevantes.

\section{Formato recolección de información}

En Excel 2010 para Windows se diseñó un formato para consignar y tabular los datos de interacciones de medicamentos, con la siguiente estructura: a) grupo farmacológico del medicamento usado concomitantemente con la medicación para el tratamiento del VHC; b) clase de interacción (medicamento-medicamento, medicamento-fitoterapéutico, medicamento-alimento); c) pareja de medicamentos que presentan la interacción; d) nivel, gravedad y probabilidad de aparición de la interacción; e) bibliografía; f) mecanismo de la interacción (farmacocinética o farmacodinámica); g) detalle del mecanismo de interacción; h) comentarios; i) recomendación.

\section{RESULTADOS}

La estrategia de búsqueda "Hepatitis C AND drug interactions OR herb-drug interactions OR food-drug interactions" arrojó 193 artículos, de los que se accedió al texto completo de 178 . De ellos, 56 reportaban IM. Por su parte, en la segunda estrategia de búsqueda, se identificaron 35 artículos, de los que se accedió al texto completo de 34. De ellos, 6 reportaban IM relacionadas con el tratamiento de VHC. Por tanto, en total se identificaron 228 artículos, de los cuales se accedió al texto completo de 212. De estos, 62 artículos cumplieron los criterios de inclusión (Figura 1). Se identificaron 206 parejas de IM, de las cuales 128 se valoraron como clínicamente relevantes (Tabla 1): $2(1,6 \%)$ Nivel 1, $110(85,9 \%)$ Nivel 2 y 16 (12,5\%) nivel 3 (Tablas 2 y 3 ). De estas 128 parejas, 120 son interacciones de mecanismo farmacocinético, en especial por inhibición enzimática 82 (64,0\%), inducción 


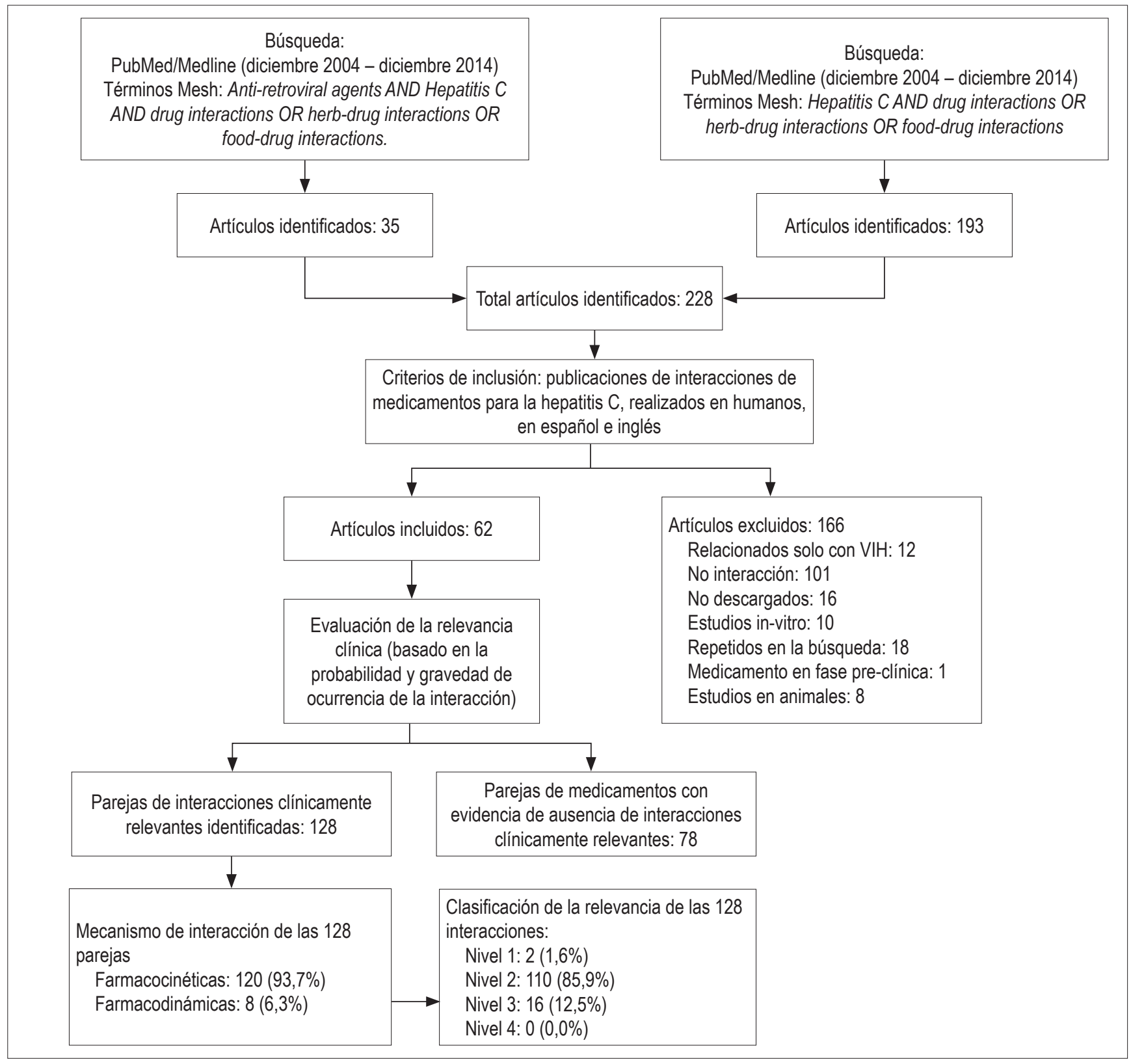

Figura 1. Esquema general del estudio Revisión estructurada. Relevancia clínica de las interacciones medicamentosas en el tratamiento de pacientes infectados con virus de hepatitis $\mathrm{C}$ genotipo 1

enzimática $35(27,3 \%)$ y cambio en la biodisponibilidad 3 $(2,4 \%)$; y 8 interacciones de mecanismo farmacodinámico. Por su parte, se identificaron 78 parejas de medicamentos con evidencia de ausencia de interacciones clínicamente relevantes, de las cuales 36 estuvieron relacionadas con telaprevir, 30 con boceprevir, 9 con sofosbuvir, 1 con rivabirina y 2 con interferón (Tabla 4).

En relación con las 8 parejas de interacciones farmacodinámicas: 3 se debieron a antagonismo entre la RIB y los
ITIAN, (abacavir, didanosina y estavudina) por la fosforilación nuclear, asociado a un aumento en la toxicidad mitocondrial y, especialmente acidosis láctica fatal (63-71,8689); 1 por sinergismo del efecto antiviral de la RIB con aciclovir (21); y 4 por sinergismo de los efectos adversos entre TLV, BOC, RIB e INF con la zidovudina, asociado a un aumento en la probabilidad de aparición de anemia y complicaciones relacionadas con toxicidad hematológica $(63-68,70,71-73,75,86,88,89)$. 
Tabla 1. Resultados generales de las 128 parejas de interacciones medicamentosas clínicamente relevantes

\begin{tabular}{|c|c|c|c|c|c|c|c|c|}
\hline \multirow{5}{*}{$\begin{array}{c}\text { Mecanismo de las } 128 \text { parejas de } \\
\text { interacciones }\end{array}$} & \multirow{5}{*}{$\begin{array}{l}\text { Farmacodinámicas } \\
8(6,3 \%) \\
\text { Farmacocinéticas } \\
120(93,7 \%)\end{array}$} & \multicolumn{7}{|c|}{ Antagonismo $3(2,4 \%)$} \\
\hline & & \multirow{2}{*}{\multicolumn{7}{|c|}{ Cambio en la biodisponibilidad $3(2,4 \%)$}} \\
\hline & & & & & & & & \\
\hline & & \multirow{2}{*}{\multicolumn{7}{|c|}{ Inhibición enzimática $82(64,0 \%)$}} \\
\hline & & & & & & & & \\
\hline \multirow{2}{*}{$\begin{array}{l}\text { Medicamento relacionado con } \\
\text { las } 120 \text { parejas de interacciones } \\
\text { farmacocinéticas }\end{array}$} & \multicolumn{3}{|c|}{ Detalle del mecanismo farmacocinético } & \multicolumn{4}{|c|}{$\begin{array}{c}\text { Relevancia clínica de la interacción } \\
\text { medicamentosa }\end{array}$} & Total \\
\hline & Inducción & Inhibición & $\begin{array}{c}\text { Cambios en } \\
\text { biodisponibilidad }\end{array}$ & $\begin{array}{l}\text { Nivel 1, } \\
\mathrm{n}(\%)\end{array}$ & $\begin{array}{l}\text { Nivel 2, } \\
\text { n (\%) }\end{array}$ & $\begin{array}{l}\text { Nivel 3, } \\
\text { n (\%) }\end{array}$ & $\begin{array}{l}\text { Nivel 4, } \\
\text { n (\%) }\end{array}$ & \\
\hline Telaprevir & 18 & 45 & 0 & $2(1,6)$ & $56(43,7)$ & $5(3,9)$ & $0(0,0)$ & 63 \\
\hline Boceprevir & 17 & 36 & 1 & $0(0,0)$ & $44(34,4)$ & $10(7,8)$ & $0(0,0)$ & 54 \\
\hline Ribavirina & 0 & 1 & 2 & $0(0,0)$ & $3(2,3)$ & $0(0,0)$ & $0(0,0)$ & 3 \\
\hline TOTAL & 35 & 82 & 3 & $2(1,6)$ & $103(80,4)$ & $15(11,7)$ & $0(0,0)$ & 120 \\
\hline
\end{tabular}

Tabla 2. Interacciones medicamentosas por inducción enzimática relacionadas con medicamentos en el tratamiento de la hepatitis $\mathrm{C}$

\begin{tabular}{|c|c|c|c|}
\hline $\begin{array}{l}\text { Grupo farmacológico o } \\
\text { medicamentos relacionados } \\
\text { con la interacción }\end{array}$ & $\begin{array}{l}\text { Medicamento } \\
\text { VHC }\end{array}$ & $\begin{array}{l}\text { Relevancia } \\
\text { clínica: } \\
\text { nivel }\end{array}$ & Comentarios y sugerencias \\
\hline $\begin{array}{l}\text { Metadona } \\
(9,10,22,24,25,26,28,29)\end{array}$ & $\mathrm{BOC} / \mathrm{TLV}$ & $\begin{array}{l}\text { 3: riesgo } \\
\text { medio }\end{array}$ & $\begin{array}{l}\text { Ambos IP pueden disminuir el ABC de la R metadona en un } 15 \%, 29 \% \text { y de la } \mathrm{S} \\
\text { metadona en un } 22 \% \text { y } 36 \% \text { respectivamente - no se requiere un ajuste de dosis }\end{array}$ \\
\hline \multicolumn{4}{|l|}{ Anticonceptivos } \\
\hline Etinil-estradiol $(27,28,85)$ & $\mathrm{BOC} / \mathrm{TLV}$ & $\begin{array}{l}\text { 2: riesgo } \\
\text { alto }\end{array}$ & $\begin{array}{l}\text { Ambos IP pueden disminuir el ABC del Etinil-estradiol en un } 25 \% \text { - monitorizar la } \\
\text { efectividad de etinil estradiol, se recomienda el uso de métodos anticonceptivos } \\
\text { no hormonales }\end{array}$ \\
\hline Norentindrona $(27,28,29)$ & $\mathrm{BOC} / \mathrm{TLV}$ & $\begin{array}{l}\text { 3: riesgo } \\
\text { medio }\end{array}$ & $\begin{array}{l}\text { Ambos IP pueden disminuir el } A B C \text { de norentindrona en un } 4 \% \text { y } 11 \% \\
\text { respectivamente - No es necesario un ajuste de dosis, se recomienda el uso de } \\
\text { métodos anticonceptivos no hormonales }\end{array}$ \\
\hline \multicolumn{4}{|l|}{ Anticonvulsivante } \\
\hline $\begin{array}{l}\text { Carbamazepina } \\
(24,27,29,30,31)\end{array}$ & $\mathrm{BOC} / \mathrm{TLV}$ & $\begin{array}{l}\text { 2: riesgo } \\
\text { alto }\end{array}$ & $\begin{array}{l}\text { La carbamazepina disminuye la concentración plasmática de ambos IP - } \\
\text { monitorizar la efectividad del boceprevir y telaprevir, un ajuste en la dosis del } \\
\text { medicamento puede ser necesario }\end{array}$ \\
\hline Fenitoina $(24,27,29,30,32)$ & $\mathrm{BOC} / \mathrm{TLV}$ & $\begin{array}{l}\text { 2: riesgo } \\
\text { alto }\end{array}$ & $\begin{array}{l}\text { La fenitoína disminuye la concentración plasmática de ambos IP - monitorizar } \\
\text { la efectividad del boceprevir y telaprevir, un ajuste en la dosis del medicamento } \\
\text { puede ser necesario }\end{array}$ \\
\hline Fenobarbital $(24,27,29,30)$ & $\mathrm{BOC} / \mathrm{TLV}$ & $\begin{array}{l}\text { 2: riesgo } \\
\text { alto }\end{array}$ & $\begin{array}{l}\text { El fenobarbital disminuye la concentración plasmática de ambos IP - monitorizar } \\
\text { la efectividad del boceprevir y telaprevir, un ajuste en la dosis del medicamento } \\
\text { puede ser necesario }\end{array}$ \\
\hline \multicolumn{4}{|c|}{ Antidepresivo/Inhibidor selectivo de la recaptación de serotonina } \\
\hline $\begin{array}{l}\text { Escitalopram } \\
(26,27,29,31,33,34)\end{array}$ & $\mathrm{BOC} / \mathrm{TLV}$ & $\begin{array}{l}\text { 2: riesgo } \\
\text { alto }\end{array}$ & $\begin{array}{l}\text { Ambos IP disminuyen el ABC de escitalopram en } 21 \% \text { y } 30 \% \text { - monitorizar } \\
\text { parámetros de efectividad de escitalopram, un ajuste de dosis podría ser necesario }\end{array}$ \\
\hline Citalopram $(30,49,45)$ & TLV & $\begin{array}{l}\text { 3: riesgo } \\
\text { medio }\end{array}$ & $\begin{array}{l}\text { Telaprevir disminuye el } \mathrm{ABC} \text { de citalopram en un } 35 \% \text { - No requiere ajuste de } \\
\text { dosis }\end{array}$ \\
\hline \multicolumn{4}{|l|}{ Antiinflamatorio esteroideo } \\
\hline Dexametasona $(27,29)$ & $\mathrm{BOC} / \mathrm{TLV}$ & $\begin{array}{l}\text { 2: riesgo } \\
\text { alto }\end{array}$ & $\begin{array}{l}\text { La dexametasona disminuye los niveles de boceprevir y telaprevir - monitorizar la } \\
\text { efectividad de los IP, no se recomienda el uso concomitante de estos medicamentos }\end{array}$ \\
\hline \multicolumn{4}{|l|}{ Antituberculosos } \\
\hline $\begin{array}{l}\text { Rifampicina } \\
(10,11,12,25,26,27,29,30,32)\end{array}$ & $\mathrm{BOC} / \mathrm{TLV}$ & $\begin{array}{l}\text { 2: riesgo } \\
\text { alto }\end{array}$ & $\begin{array}{l}\text { La rifampicina disminuye las concentraciones plasmáticas del boceprevir y } \\
\text { telaprevir hasta el } 86 \% \text { y } 92 \% \text { respectivamente - Monitorizar la efectividad del } \\
\text { boceprevir y telaprevir, un ajuste en la dosis del medicamento puede ser necesario }\end{array}$ \\
\hline
\end{tabular}


Tabla 2. Interacciones medicamentosas por inducción enzimática relacionadas con medicamentos en el tratamiento de la hepatitis C. Continuación

\begin{tabular}{|c|c|c|c|}
\hline $\begin{array}{l}\text { Grupo farmacológico o } \\
\text { medicamentos relacionados } \\
\text { con la interacción }\end{array}$ & $\begin{array}{l}\text { Medicamento } \\
\text { VHC }\end{array}$ & $\begin{array}{l}\text { Relevancia } \\
\text { clínica: } \\
\text { nivel }\end{array}$ & Comentarios y sugerencias \\
\hline \multicolumn{4}{|l|}{ ARV/ inhibidor de proteasa } \\
\hline $\begin{array}{l}\text { Atazanavir } \\
(10,11,13,14,15,16,17,18 \\
24,25,28,35,36,37,38,39,79,84)\end{array}$ & $\mathrm{BOC}$ & $\begin{array}{l}\text { 2: riesgo } \\
\text { alto }\end{array}$ & $\begin{array}{l}\text { La combinación genera una disminución en las concentraciones plasmáticas de } \\
\text { ambos medicamentos - Monitorizar la efectividad del atazanavir y Boceprevir, un } \\
\text { ajuste de dosis puede ser necesario }\end{array}$ \\
\hline $\begin{array}{l}\text { Atazanavir }(10,11,19,16,24,25 \\
27,28,35,37,38,39,40,42,43,48 \\
79,84,85)\end{array}$ & TLV & $\begin{array}{l}\text { 3: riesgo } \\
\text { medio }\end{array}$ & $\begin{array}{l}\text { Atazanavir disminuye el } \mathrm{ABC} \text { de telaprevir en un } 20 \% \text {, mientras que el } \mathrm{ABC} \text { de } \\
\text { atazanavir aumenta en un } 17 \% \text { - No se requiere un ajuste de dosis }\end{array}$ \\
\hline $\begin{array}{l}\text { Darunavir }(10,11,16,18,19,20 \\
24,27,28,35,37,38,39 \\
40,41,42,43,79,84,85)\end{array}$ & TLV & $\begin{array}{l}\text { 2: riesgo } \\
\text { alto }\end{array}$ & $\begin{array}{l}\text { La combinación genera una disminución en las concentraciones plasmáticas de } \\
\text { ambos medicamentos } 40 \% \text { para darunavir y } 35 \% \text { para telaprevir - Monitorizar la } \\
\text { efectividad de ambos medicamentos, un ajuste de dosis puede ser necesario }\end{array}$ \\
\hline $\begin{array}{l}\text { Darunavir }(10,11,13,14,16,17,20 \\
24,28,35,36,37,38,39,79,84)\end{array}$ & $\mathrm{BOC}$ & $\begin{array}{l}\text { 2: riesgo } \\
\text { alto }\end{array}$ & $\begin{array}{l}\text { La combinación genera una disminución en las concentraciones plasmáticas de } \\
\text { ambos medicamentos } 44 \% \text { para darunavir y } 32 \% \text { para boceprevir - Monitorizar la } \\
\text { efectividad del darunavir y Boceprevir, un ajuste de dosis puede ser necesario }\end{array}$ \\
\hline $\begin{array}{l}\text { Fosamprenavir }(10,17,18,24 \\
28,35,38,79)\end{array}$ & $\mathrm{BOC}$ & $\begin{array}{l}\text { 3: riesgo } \\
\text { medio }\end{array}$ & $\begin{array}{l}\text { La disminución en los niveles de ambos agentes es poco significativa - No } \\
\text { requiere ajuste de dosis }\end{array}$ \\
\hline $\begin{array}{l}\text { Fosamprenavir }(10,11,15,16 \\
18,19,24,27,28,35,38,39,40,41 \\
42,43,79,84,85)\end{array}$ & TLV & $\begin{array}{l}\text { 2: riesgo } \\
\text { alto }\end{array}$ & $\begin{array}{l}\text { Fosamprenavir disminuye en un } 32 \% \text { el } \mathrm{ABC} \text { de telaprevir, el } \mathrm{ABC} \text { de } \\
\text { fosamprenavir disminuye en un } 47 \% \text { por acción del telaprevir - monitorizar } \\
\text { efectividad de ambos medicamentos, un ajuste de dosis puede ser requerido }\end{array}$ \\
\hline $\begin{array}{l}\text { Lopinavir }(10,11,13,14,16,17 \\
18,25,28,36,37,38,39,79,84)\end{array}$ & $\mathrm{BOC}$ & $\begin{array}{l}\text { 2: riesgo } \\
\text { alto }\end{array}$ & $\begin{array}{l}\text { La combinación de lopinavir-boceprevir generan una disminución en las } \\
\text { concentraciones plasmáticas de ambos medicamentos ( } 34 \% \text { y } 45 \% \text { ) - Monitorizar } \\
\text { la efectividad de los medicamentos, un ajuste de dosis puede ser necesario }\end{array}$ \\
\hline $\begin{array}{l}\text { Lopinavir }(10,11,16,18,24,25 \\
27,28,35,37,38,39,40,42,43 \\
79,84,85)\end{array}$ & TLV & $\begin{array}{l}\text { 2: riesgo } \\
\text { alto }\end{array}$ & $\begin{array}{l}\text { La combinación de telaprevir-lopinavir generan una disminución en las concentraciones } \\
\text { plasmáticas de ambos medicamentos ( } 54 \% \text { para telaprevir) - Monitorizar la efectividad } \\
\text { de los medicamentos, un ajuste de dosis puede ser necesario }\end{array}$ \\
\hline \multicolumn{4}{|l|}{ ARV/ ITINN } \\
\hline $\begin{array}{l}\text { Efavirenz } \\
(10,11,12,19,18,24,27,28,35 \\
37,38,39,40,41,43,79,84,85)\end{array}$ & TLV & $\begin{array}{l}\text { 2: riesgo } \\
\text { alto }\end{array}$ & $\begin{array}{l}\text { El telaprevir puede disminuir las concentraciones del efavirenz, sin cambios } \\
\text { importantes clínicamente, efavirenz disminuye en un } 20 \% \text { el ABC de telaprevir- } \\
\text { Ajustar dosis de telaprevir a } 1125 \mathrm{mg} \text { cada } 8 \text { horas }\end{array}$ \\
\hline $\begin{array}{l}\text { Efavirenz } \\
(10,11,16,18,19,24,28,35,36,38 \\
39,40,41,42,44,79,84,85)\end{array}$ & $\mathrm{BOC}$ & $\begin{array}{l}\text { 2: riesgo } \\
\text { alto }\end{array}$ & $\begin{array}{l}\text { El boceprevir puede disminuir las concentraciones del efavirenz, sin cambios } \\
\text { importantes clínicamente. El efavirenz disminuye el ABC de boceprevir en un } \\
40 \% \text { - No se requiere un ajuste de dosis }\end{array}$ \\
\hline $\begin{array}{l}\text { Etravirina }(11,15,16,24,28 \\
35,38,39,79)\end{array}$ & $\mathrm{BOC}$ & $\begin{array}{l}\text { 3: riesgo } \\
\text { medio }\end{array}$ & $\begin{array}{l}\text { El boceprevir puede disminuir las concentraciones de la etravirina un } 23 \% \text {, sin } \\
\text { cambios importantes clínicamente; además el } A B C \text { de boceprevir aumenta en un } \\
10 \% \text { - No se requiere un ajuste de dosis }\end{array}$ \\
\hline Nevirapina $(11,79)$ & TLV & $\begin{array}{l}\text { 3: riesgo } \\
\text { medio }\end{array}$ & $\begin{array}{l}\text { El telaprevir puede disminuir las concentraciones de la nevirapina, sin cambios } \\
\text { importantes clínicamente - No se requiere un ajuste de dosis }\end{array}$ \\
\hline Nevirapina $(11,15,79)$ & $\mathrm{BOC}$ & $\begin{array}{l}\text { 3: riesgo } \\
\text { medio }\end{array}$ & $\begin{array}{l}\text { El boceprevir puede disminuir las concentraciones de la nevirapina, sin cambios } \\
\text { importantes clínicamente - No se requiere un ajuste de dosis }\end{array}$ \\
\hline \multicolumn{4}{|l|}{ Hipnóticos } \\
\hline Zolpidem $(24,26,27,29,30,45)$ & TLV & $\begin{array}{l}\text { 2: riesgo } \\
\text { alto }\end{array}$ & $\begin{array}{l}\text { Telaprevir disminuye el ABC de zolpidem en } 47 \% \text { - Monitorizar la efectividad del } \\
\text { zolpidem, un ajuste en la dosis del medicamento puede ser necesario }\end{array}$ \\
\hline \multicolumn{4}{|l|}{ Producto natural } \\
\hline $\begin{array}{l}\text { Hierba de San Juan }(11,25,29 \text {, } \\
30,32,47)\end{array}$ & $\mathrm{BOC} / \mathrm{TLV}$ & $\begin{array}{l}\text { 2: riesgo } \\
\text { alto }\end{array}$ & $\begin{array}{l}\text { La hierba de San Juan puede inducir la CYP3A4 y aumentar el metabolismo del } \\
\text { ARV, lo que puede causar una disminución en sus concentraciones plasmáticas } \\
\text { y en la respuesta virológica - Monitorizar parámetros de efectividad de ARV y } \\
\text { realizar un seguimiento más continúo a la carga viral }\end{array}$ \\
\hline
\end{tabular}

ABC: área bajo la curva; ARV: agente antiretroviral; BOC: boceprevir; IP: inhibidor de proteasa; IP: Inhibidores de proteasa sérica; ITINN: inhibidores de transcriptasa inversa no nucleósidicos; TLV: telaprevir. 
Tabla 3. Interacciones medicamentosas por inhibición relacionados con medicamentos en el tratamiento de la hepatitis C

\begin{tabular}{|c|c|c|c|}
\hline $\begin{array}{l}\text { Grupo farmacológico o } \\
\text { medicamentos relacionados } \\
\text { con la interacción }\end{array}$ & $\begin{array}{l}\text { Medicamento } \\
\text { VHC }\end{array}$ & $\begin{array}{l}\text { Relevancia } \\
\text { clínica: } \\
\text { nivel }\end{array}$ & Comentarios y sugerencias \\
\hline \multicolumn{4}{|l|}{ Analgésico no esteroideo } \\
\hline Celecoxib (30) & BOC/TLV & $\begin{array}{l}\text { 2: riesgo } \\
\text { alto }\end{array}$ & $\begin{array}{l}\text { Ambos IP inhiben el CYP3A4, aumentando los niveles de celecoxib - monitorizar la } \\
\text { seguridad del celecoxib un ajuste de dosis puede ser necesario }\end{array}$ \\
\hline \multicolumn{4}{|l|}{ Analgésico opioide } \\
\hline Buprenorfina $(9,10,24,26)$ & $\mathrm{BOC}$ & $\begin{array}{l}\text { 3: riesgo } \\
\text { medio }\end{array}$ & $\begin{array}{l}\text { El boceprevir puede aumentar el } A B C \text { de la buprenorfina en un } 19 \% \text { - No se } \\
\text { requiere un ajuste de dosis }\end{array}$ \\
\hline \multicolumn{4}{|l|}{ Anestésico/benzodiacepina } \\
\hline $\begin{array}{l}\text { Midazolam }(10,11,24,27,26 \\
30,32)\end{array}$ & $\mathrm{BOC}$ & $\begin{array}{l}\text { 2: riesgo } \\
\text { alto }\end{array}$ & $\begin{array}{l}\text { Boceprevir aumenta el ABC del midazolam oral en } 430 \% \text {. - Monitorizar la seguridad } \\
\text { del midazolam, no se recomiendo su uso concomitante }\end{array}$ \\
\hline $\begin{array}{l}\text { Midazolam } \\
(11,24,27,26,29,30,32)\end{array}$ & TLV & $\begin{array}{l}\text { 2: riesgo } \\
\text { alto }\end{array}$ & $\begin{array}{l}\text { Telaprevir aumenta el ABC del midazolam oral en } 796 \% \text { - Monitorizar la seguridad } \\
\text { del midazolam, no se recomiendo su uso concomitante }\end{array}$ \\
\hline Midazolam IV $(27,29)$ & TLV & $\begin{array}{l}\text { 1: riesgo } \\
\text { muy alto }\end{array}$ & $\begin{array}{l}\text { Telaprevir puede aumentar el ABC del midazolam IV en } 240 \% \text { - No se recomienda } \\
\text { su uso concomitante }\end{array}$ \\
\hline \multicolumn{4}{|l|}{ Ansiolítico } \\
\hline Alprazolam $(10,24,27,29,30)$ & TLV & $\begin{array}{l}\text { 2: riesgo } \\
\text { alto }\end{array}$ & $\begin{array}{l}\text { Telaprevir aumenta el ABC de alprazolam en } 35 \% \text { - Monitorizar la seguridad del } \\
\text { alprazolam, un ajuste en la dosis del medicamento puede ser necesario }\end{array}$ \\
\hline \multicolumn{4}{|l|}{ Antianginoso/antiarrítmico } \\
\hline Sotalol (30) & TLV & $\begin{array}{l}\text { 2: riesgo } \\
\text { alto }\end{array}$ & $\begin{array}{l}\text { Telaprevir inhibe CYP3A4, pudiendo elevar los niveles de sotalol-monitorizar } \\
\text { la seguridad del sotalol, no se recomienda el uso concomitante de estos } \\
\text { medicamentos }\end{array}$ \\
\hline \multicolumn{4}{|l|}{ Antiarrítmico } \\
\hline Amiodarona $(26,29,30)$ & TLV & $\begin{array}{l}\text { 2: riesgo } \\
\text { alto }\end{array}$ & $\begin{array}{l}\text { Telaprevir inhibe CYP3A4, pudiendo elevar los niveles de amiodarona - monitorizar } \\
\text { la seguridad de amiodarona, no se recomienda el uso concomitante de estos } \\
\text { medicamentos }\end{array}$ \\
\hline Quinidina (30) & TLV & $\begin{array}{l}\text { 2: riesgo } \\
\text { alto }\end{array}$ & $\begin{array}{l}\text { Telaprevir inhibe CYP3A4, pudiendo elevar los niveles de quinidina-monitorizar } \\
\text { la seguridad de quinidina, no se recomienda el uso concomitante de estos } \\
\text { medicamentos }\end{array}$ \\
\hline \multicolumn{4}{|l|}{ Antiarrítmicos/inotrópico } \\
\hline Digoxina (26) & $\mathrm{BOC}$ & $\begin{array}{l}\text { 2: riesgo } \\
\text { alto }\end{array}$ & $\begin{array}{l}\text { Boceprevir aumenta el ABC de digoxina en un 19\% - Monitorizar parámetros de } \\
\text { seguridad del digoxina, considerar un ajuste de dosis }\end{array}$ \\
\hline Digoxina $(24,26,27,29,30)$ & TLV & $\begin{array}{l}\text { 1: riesgo } \\
\text { muy alto }\end{array}$ & $\begin{array}{l}\text { Telaprevir aumenta el ABC de digoxina en un 85\% - No se recomienda esta } \\
\text { combinación }\end{array}$ \\
\hline \multicolumn{4}{|l|}{ Antiasmático } \\
\hline Budesonida (30) & $\mathrm{BOC} / \mathrm{TLV}$ & $\begin{array}{l}\text { 2: riesgo } \\
\text { alto }\end{array}$ & $\begin{array}{l}\text { Ambos IPs inhiben CYP3A4, pudiendo elevar los niveles de budesonida - } \\
\text { Monitorizar la seguridad de budesonida, no se recomienda el uso concomitante de } \\
\text { estos medicamentos }\end{array}$ \\
\hline Salmeterol (29) & TLV & $\begin{array}{l}\text { 2: riesgo } \\
\text { alto }\end{array}$ & $\begin{array}{l}\text { Telaprevir inhibe CYP3A4, pudiendo elevar los niveles de salmeterol - Monitorizar } \\
\text { la seguridad de salmeterol, especialmente un aumento en el intervalo QT, no se } \\
\text { recomienda el uso concomitante de estos medicamentos }\end{array}$ \\
\hline \multicolumn{4}{|l|}{ Antibiótico/macrólido } \\
\hline Claritromicina $(27,29,30)$ & TLV & $\begin{array}{l}\text { 2: riesgo } \\
\text { alto }\end{array}$ & $\begin{array}{l}\text { Telaprevir inhibe CYP3A4, generando un aumento en el ABC de los dos } \\
\text { medicamentos - Monitorizar la seguridad del IPs y macrólido, un ajuste de dosis } \\
\text { puede ser necesario. Considerar el uso de azitromicina }\end{array}$ \\
\hline Claritromicina $(26,27,30,42)$ & $\mathrm{BOC}$ & $\begin{array}{l}\text { 3: riesgo } \\
\text { medio }\end{array}$ & $\begin{array}{l}\text { Claritromicina aumenta en un } 21 \% \text { el ABC de boceprevir - No requiere ajuste de } \\
\text { dosis }\end{array}$ \\
\hline Eritromicina $(29,30)$ & $\mathrm{BOC} / \mathrm{TLV}$ & $\begin{array}{l}\text { 2: riesgo } \\
\text { alto }\end{array}$ & $\begin{array}{l}\text { Ambos IP inhiben CYP3A4, generando un aumento en el ABC de los dos } \\
\text { medicamentos - Monitorizar la seguridad del IP y macrólido, un ajuste de dosis } \\
\text { puede ser necesario. Considerar el uso de azitromicina }\end{array}$ \\
\hline
\end{tabular}


Tabla 3. Interacciones medicamentosas por inhibición relacionados con medicamentos en el tratamiento de la hepatitis C. Continuación

\begin{tabular}{|c|c|c|c|}
\hline $\begin{array}{l}\text { Grupo farmacológico o } \\
\text { medicamentos relacionados } \\
\text { con la interacción }\end{array}$ & $\begin{array}{l}\text { Medicamento } \\
\text { VHC }\end{array}$ & $\begin{array}{l}\text { Relevancia } \\
\text { clínica: } \\
\text { nivel }\end{array}$ & Comentarios y sugerencias \\
\hline \multicolumn{4}{|l|}{ Anticonceptivo } \\
\hline Drospirenona $(27,30,32,85)$ & $\mathrm{BOC}$ & $\begin{array}{l}\text { 2: riesgo } \\
\text { alto }\end{array}$ & $\begin{array}{l}\text { Boceprevir aumenta el ABC de drospirenona en un 99\% - Monitorizar seguridad de } \\
\text { drospirenona, no se recomienda el uso concomitante de ambos medicamentos }\end{array}$ \\
\hline \multicolumn{4}{|l|}{ Antidepresivo atípico } \\
\hline Bupropión (30) & BOC/TLV & $\begin{array}{l}\text { 2: riesgo } \\
\text { alto }\end{array}$ & $\begin{array}{l}\text { Ambos IP inhiben CYP3A4, aumentando los niveles plasmáticos de bupropion - } \\
\text { monitorizar la seguridad del bupropión, un ajuste de dosis puede ser necesario }\end{array}$ \\
\hline Trazodona (29) & TLV & $\begin{array}{l}\text { 2: riesgo } \\
\text { alto }\end{array}$ & $\begin{array}{l}\text { Telaprevir inhibe CYP3A4, aumentando los niveles de trazodona - Monitorizar la } \\
\text { seguridad de trazodona, un ajuste de dosis puede ser necesario }\end{array}$ \\
\hline \multicolumn{4}{|l|}{ Antiemético } \\
\hline Domperidona $(27,29,30)$ & TLV & $\begin{array}{l}\text { 2: riesgo } \\
\text { alto }\end{array}$ & $\begin{array}{l}\text { Telaprevir inhibe CYP3A4, aumentando así los niveles de domperidona - } \\
\text { Monitorizar los parámetros de seguridad de domperidona, un ajuste de dosis puede } \\
\text { ser necesario, considerar el uso de metoclopramida }\end{array}$ \\
\hline \multicolumn{4}{|l|}{ Antihipertensivo pulmonar } \\
\hline Bosentan $(30,50)$ & TLV & $\begin{array}{l}\text { 2: riesgo } \\
\text { alto }\end{array}$ & $\begin{array}{l}\text { Telaprevir inhibe CYP3A4 y Pg-p, aumentando así los niveles de bosentan } \\
\text { hasta } 4 \text { veces - Monitorizar la seguridad del bosentan un ajuste en la dosis del } \\
\text { medicamento puede ser necesario, considerar el uso de Ambrisentan }\end{array}$ \\
\hline \multicolumn{4}{|c|}{ Antihipertensivo/bloqueador de canales de calcio } \\
\hline $\begin{array}{l}\text { Amlodipino } \\
(10,21,24,26,27,29,30,85)\end{array}$ & TLV & $\begin{array}{l}\text { 2: riesgo } \\
\text { alto }\end{array}$ & $\begin{array}{l}\text { El telaprevir aumenta el ABC de amlodipino en } 179 \% \text { - Monitorizar la seguridad del } \\
\text { amlodipino, iniciar con dosis bajas y ajustar dosis acorde a respuesta }\end{array}$ \\
\hline Bepridil $(26,29,30)$ & $\mathrm{BOC} / \mathrm{TLV}$ & $\begin{array}{l}\text { 2: riesgo } \\
\text { alto }\end{array}$ & $\begin{array}{l}\text { Ambos IP inhiben CYP3A4, aumentando los niveles de bepridil - Monitorizar } \\
\text { seguridad de bepridil, no se recomienda el uso concomitante de estos } \\
\text { medicamentos }\end{array}$ \\
\hline Diltiazem $(29,30)$ & TLV & $\begin{array}{l}\text { 2: riesgo } \\
\text { alto }\end{array}$ & $\begin{array}{l}\text { Telaprevir inhibe CYP3A4, aumentando los niveles de diltiazem - monitorizar los } \\
\text { parámetros de seguridad de diltiazem, un ajuste de dosis puede ser necesario, } \\
\text { considerar el uso de amlodipino en dosis bajas }\end{array}$ \\
\hline \multicolumn{4}{|l|}{ Antiinflamatorio esteroideo } \\
\hline Prednisolona (28) & $\mathrm{BOC}$ & $\begin{array}{l}\text { 3: riesgo } \\
\text { medio }\end{array}$ & Boceprevir aumenta el ABC de prednisolona en $37 \%$ - No requiere ajuste de dosis \\
\hline Prednisona (28) & $\mathrm{BOC}$ & $\begin{array}{l}\text { 3: riesgo } \\
\text { medio }\end{array}$ & Boceprevir aumenta el ABC de prednisona en $22 \%$ - No requiere ajuste de dosis \\
\hline \multicolumn{4}{|l|}{ Antimicótico } \\
\hline Itraconazol (29) & TLV & $\begin{array}{l}\text { 2: riesgo } \\
\text { alto }\end{array}$ & $\begin{array}{l}\text { Esta combinación produce un aumento en el ABC de itraconazol de } 225 \% \text { - } \\
\text { Monitorizar la seguridad de ambos medicamentos, un ajuste en la dosis de los } \\
\text { medicamentos puede ser necesario. La dosis de itraconazol no debe exceder los } \\
200 \mathrm{mg} / \text { día }\end{array}$ \\
\hline $\begin{array}{l}\text { Ketoconazol } \\
(10,12,26,27,29)\end{array}$ & TLV & $\begin{array}{l}\text { 2: riesgo } \\
\text { alto }\end{array}$ & $\begin{array}{l}\text { Con esta combinación se pueden aumentar las concentraciones plasmáticas del } \\
\text { telaprevir y ketoconazol en } 62 \% \text { y de } 46 \% \text { a } 125 \% \text { respectivamente - Monitorizar } \\
\text { la seguridad de ambos medicamentos, un ajuste en la dosis de los medicamentos } \\
\text { puede ser necesario. La dosis de ketoconazol no debe exceder los } 200 \mathrm{mg} / \text { día }\end{array}$ \\
\hline Ketoconazol $(26,27,42)$ & $\mathrm{BOC}$ & $\begin{array}{l}\text { 2: riesgo } \\
\text { alto }\end{array}$ & $\begin{array}{l}\text { Esta combinación produce un aumento en el ABC de boceprevir de } 131 \% \text { - } \\
\text { Monitorizar la seguridad de ambos medicamentos, un ajuste en la dosis de los } \\
\text { medicamentos puede ser necesario. La dosis de ketoconazol no debe exceder los } \\
200 \mathrm{mg} / \text { día }\end{array}$ \\
\hline Voriconazol (30) & $\mathrm{BOC} / \mathrm{TLV}$ & $\begin{array}{l}\text { 2: riesgo } \\
\text { alto }\end{array}$ & $\begin{array}{l}\text { Voriconazol inhibe CYP3A4, aumentado los niveles de boceprevir y telaprevir } \\
\text { - Monitorizar seguridad de los IPs, un ajuste de dosis puede ser necesario, } \\
\text { considerar el uso de fluconazol }\end{array}$ \\
\hline
\end{tabular}


Tabla 3. Interacciones medicamentosas por inhibición relacionados con medicamentos en el tratamiento de la hepatitis C. Continuación

\begin{tabular}{|c|c|c|c|}
\hline $\begin{array}{l}\text { Grupo farmacológico o } \\
\text { medicamentos relacionados } \\
\text { con la interacción }\end{array}$ & $\begin{array}{l}\text { Medicamento } \\
\text { VHC }\end{array}$ & $\begin{array}{l}\text { Relevancia } \\
\text { clínica: } \\
\text { nivel }\end{array}$ & Comentarios y sugerencias \\
\hline \multicolumn{4}{|l|}{ Antimigrañoso/alcaloides del ergot } \\
\hline $\begin{array}{l}\text { Dihidroergotamina } \\
(11,29,30,32)\end{array}$ & $\mathrm{BOC} / \mathrm{TLV}$ & $\begin{array}{l}\text { 2: riesgo } \\
\text { alto }\end{array}$ & $\begin{array}{l}\text { Ambos IP aumentan las concentraciones plasmáticas de la dihidro-ergotamina - } \\
\text { Monitorizar los parámetros de seguridad de la dihidro-ergotamina, un ajuste de } \\
\text { dosis puede ser necesario }\end{array}$ \\
\hline Ergonovina $(11,29,30)$ & $\mathrm{BOC} / \mathrm{TLV}$ & $\begin{array}{l}\text { 2: riesgo } \\
\text { alto }\end{array}$ & $\begin{array}{l}\text { Ambos IP aumentan las concentraciones plasmáticas de la ergonovina - Monitorizar } \\
\text { los parámetros de seguridad de la ergonovina, un ajuste de dosis puede ser } \\
\text { necesario }\end{array}$ \\
\hline Ergotamina $(11,29,30)$ & $\mathrm{BOC} / \mathrm{TLV}$ & $\begin{array}{l}\text { 2: riesgo } \\
\text { alto }\end{array}$ & $\begin{array}{l}\text { Ambos IP aumentan las concentraciones plasmáticas de la ergotamina - } \\
\text { Monitorizar los parámetros de seguridad de la ergotamina, un ajuste de dosis } \\
\text { puede ser necesario }\end{array}$ \\
\hline Metilergonovina $(11,29,30)$ & $\mathrm{BOC} / \mathrm{TLV}$ & $\begin{array}{l}\text { 2: riesgo } \\
\text { alto }\end{array}$ & $\begin{array}{l}\text { Ambos IP aumentan las concentraciones plasmáticas de la metilergonovina - } \\
\text { Monitorizar los parámetros de seguridad de la metilergonovina, un ajuste de dosis } \\
\text { puede ser necesario }\end{array}$ \\
\hline \multicolumn{4}{|l|}{ Antipalúdico } \\
\hline Halofrantina (30) & $\mathrm{BOC} / \mathrm{TLV}$ & $\begin{array}{l}\text { 2: riesgo } \\
\text { alto }\end{array}$ & $\begin{array}{l}\text { Ambos IP inhiben CYP3A4, aumentando los niveles de halofrantina - Monitorizar } \\
\text { seguridad de halofrantina, no se recomienda el uso concomitante de estos } \\
\text { medicamentos }\end{array}$ \\
\hline Lumefrantina (30) & $\mathrm{BOC} / \mathrm{TLV}$ & $\begin{array}{l}\text { 2: riesgo } \\
\text { alto }\end{array}$ & $\begin{array}{l}\text { Ambos IP inhiben CYP3A4, aumentando los niveles de lumefrantina - Monitorizar } \\
\text { seguridad de lumefrantina, no se recomienda el uso concomitante de estos } \\
\text { medicamentos }\end{array}$ \\
\hline \multicolumn{4}{|l|}{ Antisicótico/típico } \\
\hline Pimozida $(11,30,32)$ & $\mathrm{BOC} / \mathrm{TLV}$ & $\begin{array}{l}\text { 2: riesgo } \\
\text { alto }\end{array}$ & $\begin{array}{l}\text { Ambos IP aumentan las concentraciones plasmáticas de la pimozida - Monitorizar } \\
\text { los parámetros de seguridad de la pimozida, un ajuste de dosis puede ser } \\
\text { necesario }\end{array}$ \\
\hline \multicolumn{4}{|l|}{ ARV/inhibidor de fusión } \\
\hline Maraviroc $(28,39,79)$ & $\mathrm{BOC} / \mathrm{TLV}$ & $\begin{array}{l}\text { 2: riesgo } \\
\text { alto }\end{array}$ & $\begin{array}{l}\text { Boceprevir aumenta los niveles de maraviroc } 3 \text { veces, mientras que telaprevir lo } \\
\text { hace } 9,5 \text { veces - monitorizar la seguridad del maraviroc, un ajuste en la dosis del } \\
\text { medicamento puede ser necesario. Se recomienda una dosis de maraviroc de } 150 \\
\text { mg dos veces día }\end{array}$ \\
\hline \multicolumn{4}{|l|}{ Arv/itinn } \\
\hline $\begin{array}{l}\text { Rilpivirina } \\
(11,15,28,35,38,39)\end{array}$ & TLV & $\begin{array}{l}\text { 2: riesgo } \\
\text { alto }\end{array}$ & $\begin{array}{l}\text { Telaprevir aumenta el ABC de rilpivirina en } 78 \% \text { - Monitorizar los parámetros de } \\
\text { seguridad de la rilpivirina, un ajuste de dosis puede ser necesario }\end{array}$ \\
\hline $\begin{array}{l}\text { Rilpivirina } \\
(11,28,35,38,39,51)\end{array}$ & $\mathrm{BOC}$ & $\begin{array}{l}\text { 3: riesgo } \\
\text { medio }\end{array}$ & $\begin{array}{l}\text { Boceprevir aumenta el } \mathrm{ABC} \text { de rilpivirina, sin ser clínicamente significativo, mientras } \\
\text { que los niveles de boceprevir permanecen sin variar - No requiere ajuste de dosis }\end{array}$ \\
\hline \multicolumn{4}{|l|}{ Citostático } \\
\hline Imatinib (30) & $\mathrm{BOC} / \mathrm{TLV}$ & $\begin{array}{l}\text { 2: riesgo } \\
\text { alto }\end{array}$ & $\begin{array}{l}\text { Ambos IP inhiben CYP3A4, aumentando los niveles de imatinib - Monitorizar } \\
\text { seguridad de imatinib, no se recomienda el uso concomitante de estos } \\
\text { medicamentos }\end{array}$ \\
\hline Sunitinib (30) & $\mathrm{BOC} / \mathrm{TLV}$ & $\begin{array}{l}\text { 2: riesgo } \\
\text { alto }\end{array}$ & $\begin{array}{l}\text { Ambos IP inhiben CYP3A4, aumentando así los niveles de sunitinib - Monitorizar } \\
\text { seguridad de sunitinib, no se recomienda el uso concomitante de estos } \\
\text { medicamentos }\end{array}$ \\
\hline \multicolumn{4}{|l|}{ Coadyuvante tratamiento gota } \\
\hline Colchicina $(29)$ & TLV & $\begin{array}{l}\text { 2: riesgo } \\
\text { alto }\end{array}$ & $\begin{array}{l}\text { Taleprevir inhibe CYP3A4, aumentado los niveles de colchicina - Por ser la } \\
\text { colchicina de estrecho margen terapéutico, no se recomienda el uso concomitante } \\
\text { de ambos medicamentos }\end{array}$ \\
\hline
\end{tabular}


Tabla 3. Interacciones medicamentosas por inhibición relacionados con medicamentos en el tratamiento de la hepatitis C. Continuación

\begin{tabular}{|c|c|c|c|}
\hline $\begin{array}{l}\text { Grupo farmacológico o } \\
\text { medicamentos relacionados } \\
\text { con la interacción }\end{array}$ & $\begin{array}{l}\text { Medicamento } \\
\text { VHC }\end{array}$ & $\begin{array}{l}\text { Relevancia } \\
\text { clínica: } \\
\text { nivel }\end{array}$ & Comentarios y sugerencias \\
\hline \multicolumn{4}{|l|}{ Hipnótico/benzodiacepinas } \\
\hline Triazolam $(11,27,29,30)$ & BOC/TLV & $\begin{array}{l}\text { 2: riesgo } \\
\text { alto }\end{array}$ & $\begin{array}{l}\text { Ambos antiretrovirales aumentan las concentraciones plasmáticas de triazolam - } \\
\text { Monitorizar los parámetros de seguridad del triazolam, un ajuste de dosis puede ser } \\
\text { necesario }\end{array}$ \\
\hline \multicolumn{4}{|l|}{ Hipolipemiante/estatina } \\
\hline $\begin{array}{l}\text { Atorvastatina }(11,24,26,27 \text {, } \\
29,30,32,33,41,52,85)\end{array}$ & $\mathrm{BOC} / \mathrm{TLV}$ & $\begin{array}{l}\text { 2: riesgo } \\
\text { alto }\end{array}$ & $\begin{array}{l}\text { Boceprevir aumenta el ABC de atorvastatina en } 270 \% \text {, mientras que telaprevir en } \\
688 \% \text { - Monitorizar los parámetros de seguridad de atorvastatina, un ajuste de } \\
\text { dosis puede ser necesario }\end{array}$ \\
\hline Lovastatina $(10,11,30,32)$ & $\mathrm{BOC} / \mathrm{TLV}$ & $\begin{array}{l}\text { 2: riesgo } \\
\text { alto }\end{array}$ & $\begin{array}{l}\text { Ambos antirretrovirales aumentan las concentraciones plasmáticas de lovastatina } \\
\text { - Monitorizar los parámetros de seguridad de lovastatina, un ajuste de dosis puede } \\
\text { ser necesario }\end{array}$ \\
\hline $\begin{array}{l}\text { Simvastatina } \\
(10,11,30,32,34)\end{array}$ & $\mathrm{BOC} / \mathrm{TLV}$ & $\begin{array}{l}\text { 2: riesgo } \\
\text { alto }\end{array}$ & $\begin{array}{l}\text { Ambos IP aumentan las concentraciones plasmáticas de simvastatina - Monitorizar } \\
\text { los parámetros de seguridad de simvastatina, un ajuste de dosis puede ser } \\
\text { necesario }\end{array}$ \\
\hline \multicolumn{4}{|l|}{ Inmunosupresor } \\
\hline Azatioprina (46) & $\mathrm{RIB}$ & $\begin{array}{l}\text { 2: riesgo } \\
\text { alto }\end{array}$ & $\begin{array}{l}\text { Ribavirina inhibe inosina monofosfato deshidrogenasa, una enzima presente en } \\
\text { una de las vías metabólicas de la azatioprina, llevando a la acumulación de un } \\
\text { metabolito responsable de la mielosupresión y la pancitonemia - Retirar azatioprina } \\
\text { y evaluar el uso de otro agente inmunosupresor }\end{array}$ \\
\hline $\begin{array}{l}\text { Ciclosporina }(10,23,24,26 \\
27,28,29,30,41,44,53,54 \\
55,56,57,85)\end{array}$ & $\mathrm{BOC} / \mathrm{TLV}$ & $\begin{array}{l}\text { 2: riesgo } \\
\text { alto }\end{array}$ & $\begin{array}{l}\text { Ambos IP aumentan las concentraciones plasmáticas de ciclosporina; el boceprevir } \\
\text { la aumenta en } 2,2 \text { veces y telaprevir aumenta el ABC en } 364 \% \text { - Monitorizar los } \\
\text { parámetros de seguridad de ciclosporina, un ajuste de dosis puede ser necesario }\end{array}$ \\
\hline $\begin{array}{l}\text { Sirolimus } \\
(10,27,28,29,49,55,85)\end{array}$ & BOC/TLV & $\begin{array}{l}\text { 2: riesgo } \\
\text { alto }\end{array}$ & $\begin{array}{l}\text { Ambos IP aumentan los niveles de sirolimus, el telaprevir aumenta el ABC de } \\
\text { sirolimus en } 26,1 \text { veces - Monitorizar la seguridad del sirolimus un ajuste en la } \\
\text { dosis del medicamento puede ser necesario }\end{array}$ \\
\hline $\begin{array}{l}\text { Tacrolimus }(10,24,27,28,29 \\
44,53,54,55,56,85)\end{array}$ & BOC/TLV & $\begin{array}{l}\text { 2: riesgo } \\
\text { alto }\end{array}$ & $\begin{array}{l}\text { Ambos IP aumentan el ABC de tacrolimus, el telaprevir lo hace } 6900 \% \text { y boceprevir } \\
1600 \% \text { - monitorizar la seguridad del tacrolimus un ajuste en la dosis del } \\
\text { medicamento puede ser necesario }\end{array}$ \\
\hline \multicolumn{4}{|l|}{ Procinético } \\
\hline Cisaprida $(10,29,30,32)$ & $\mathrm{BOC} / \mathrm{TLV}$ & $\begin{array}{l}\text { 2: riesgo } \\
\text { alto }\end{array}$ & $\begin{array}{l}\text { Ambos IP aumentan las concentraciones plasmáticas de cisaprida - Monitorizar los } \\
\text { parámetros de seguridad de cisaprida, no se recomienda el uso concomitante de } \\
\text { ambos medicamentos }\end{array}$ \\
\hline \multicolumn{4}{|c|}{ Tratamiento de la hiperplasia prostática benigna } \\
\hline Alfuzosina $(11,27,29,30,32)$ & BOC/TLV & $\begin{array}{l}\text { 2: riesgo } \\
\text { alto }\end{array}$ & $\begin{array}{l}\text { Ambos IP aumentan las concentraciones plasmáticas de alfuzosina - Monitorizar } \\
\text { los parámetros de seguridad de alfuzosina, un ajuste de dosis puede ser necesario }\end{array}$ \\
\hline \multicolumn{4}{|c|}{ Tratamiento disfunción eréctil/inhibidor de fosfodiesterasa- 5} \\
\hline $\begin{array}{l}\text { Sildenafil } \\
(11,25,27,29,30,32)\end{array}$ & BOC/TLV & $\begin{array}{l}\text { 2: riesgo } \\
\text { alto }\end{array}$ & $\begin{array}{l}\text { Ambos IP aumentan las concentraciones plasmáticas de sildenafil - se podría } \\
\text { ajustar la dosis de sildenafil a } 25 \mathrm{mg} / 48 \text { horas }\end{array}$ \\
\hline Tadalafil $(11,27,29,30)$ & $\mathrm{BOC} / \mathrm{TLV}$ & $\begin{array}{l}\text { 2: riesgo } \\
\text { alto }\end{array}$ & $\begin{array}{l}\text { Ambos IP aumentan las concentraciones plasmáticas de tadalafil - se podría ajustar } \\
\text { la dosis de tadalafil a } 10 \mathrm{mg} / 72 \text { horas }\end{array}$ \\
\hline
\end{tabular}

ABC: área bajo la curva; ARV: agente antiretroviral; BOC: boceprevir; IP: Inhibidores de proteasa sérica; ITINN: inhibidores de transcriptasa inversa no nucleosídicos; RIB: ribavirina; TLV: telaprevir. 
Tabla 4. Medicamentos sin evidencia de interacciones clínicamente relevantes

\begin{tabular}{|c|c|c|}
\hline $\begin{array}{l}\text { Grupo farmacológico o medicamentos } \\
\text { relacionados con la interacción }\end{array}$ & $\begin{array}{l}\text { Medicamento } \\
\text { VHC }\end{array}$ & Comentario \\
\hline \multicolumn{3}{|l|}{ Analgésico opioide } \\
\hline Buprenorfina $(9,10,24,29)$ & TLV & $\begin{array}{l}\text { Telaprevir disminuye en un } 4 \% \text { el AUC de buprenorfina, Interacción sin relevancia } \\
\text { clínica }\end{array}$ \\
\hline Buprenorfina (9) & Sofosbuvir & $\begin{array}{l}\text { El sofosbuvir no tiene afinidad ni interactúa con ningún citocromo del CYP450. No } \\
\text { convergen rutas metabólicas, interacción sin relevancia clínica }\end{array}$ \\
\hline Metadona $(9,26,58,59,60)$ & $\operatorname{lnf}$ & Interacción sin relevancia clínica \\
\hline Metadona (61) & Sofosbuvir & $\begin{array}{l}\text { El sofosbuvir no tiene afinidad ni interactúa con ningún citocromo del CYP450. No } \\
\text { convergen rutas metabólicas, interacción sin relevancia clínica }\end{array}$ \\
\hline Metadona (60) & $\mathrm{RIB}$ & Interacción sin relevancia clínica \\
\hline \multicolumn{3}{|l|}{ Anestésico } \\
\hline Propofol (26) & $\mathrm{BOC} / \mathrm{TLV}$ & $\begin{array}{l}\text { Propofol se metaboliza por CYP2B6, además tiene metabolismo extra hepático y } \\
\text { excreción extra renal }\end{array}$ \\
\hline \multicolumn{3}{|l|}{ Antibiótico } \\
\hline Aminoglucósidos IV (33) & BOC/TLV & Interacción sin relevancia clínica \\
\hline Amoxicilina (33) & $\mathrm{BOC} / \mathrm{TLV}$ & Interacción sin relevancia clínica \\
\hline Azitromicina (33) & $\mathrm{BOC} / \mathrm{TLV}$ & Interacción sin relevancia clínica \\
\hline Cefalosporinas de tercera generación (33) & BOC/TLV & Interacción sin relevancia clínica \\
\hline Ciprofloxacina (33) & BOC/TLV & Interacción sin relevancia clínica \\
\hline \multicolumn{3}{|l|}{ Anticonvulsivantes } \\
\hline Ácido valproico $(29,31,33)$ & BOC/TLV & Interacción sin relevancia clínica \\
\hline Gabapentina $(24,31)$ & BOC/TLV & No convergen rutas metabólicas, interacción sin relevancia clínica \\
\hline Lamotrigina $(29,31)$ & BOC/TLV & No convergen rutas metabólicas, interacción sin relevancia clínica \\
\hline Leviracetam (29) & TLV & Interacción sin relevancia clínica \\
\hline Pregabalina $(24,31)$ & BOC/TLV & No convergen rutas metabólicas, interacción sin relevancia clínica \\
\hline \multicolumn{3}{|c|}{ Antidepresivo/ inhibidor selectivo de la recaptación de serotonina } \\
\hline Fluoxetina $(24,31)$ & & $\begin{array}{l}\text { Fluoxetina se metaboliza por CYP2D6, No convergen rutas metabólicas, interacción } \\
\text { sin relevancia clínica }\end{array}$ \\
\hline Paroxetina $(24,31)$ & BOC/TLV & $\begin{array}{l}\text { Paroxetina se metaboliza por CYP2D6, No convergen rutas metabólicas, interacción } \\
\text { sin relevancia clínica }\end{array}$ \\
\hline \multicolumn{3}{|l|}{ Antidiabético } \\
\hline Metformina $(11,26,29,30,32)$ & BOC/TLV & Interacción sin relevancia clínica \\
\hline Repaglinida (29) & TLV & $\begin{array}{l}\text { La repaglinida se metaboliza parcialmente por CYP3A4, pero tiene como vía de } \\
\text { escape metabolismo por CYP2C8, interacción sin relevancia clínica }\end{array}$ \\
\hline \multicolumn{3}{|l|}{ Antihipertensivos } \\
\hline Atenolol $(26,33)$ & $\mathrm{BOC} / \mathrm{TLV}$ & Interacción sin relevancia clínica \\
\hline Propranolol (33) & $\mathrm{BOC} / \mathrm{TLV}$ & Interacción sin relevancia clínica \\
\hline Enalapril (33) & BOC/TLV & Interacción sin relevancia clínica \\
\hline Ramipril (33) & $\mathrm{BOC} / \mathrm{TLV}$ & Interacción sin relevancia clínica \\
\hline \multicolumn{3}{|l|}{ Antihistamínicos } \\
\hline Desloratadina (33) & BOC/TLV & Interacción sin relevancia clínica \\
\hline Difenhidramina (30) & $\mathrm{BOC} / \mathrm{TLV}$ & Interacción sin relevancia clínica \\
\hline Levocetirizina (33) & $\mathrm{BOC} / \mathrm{TLV}$ & Interacción sin relevancia clínica \\
\hline \multicolumn{3}{|l|}{ Antipsicóticos atípicos } \\
\hline Olanzapina $(24,31)$ & $\mathrm{BOC} / \mathrm{TLV}$ & $\begin{array}{l}\text { Olanzapina es metabolizado por el CYP1A2, No convergen rutas metabólicas, } \\
\text { interacción sin relevancia clínica }\end{array}$ \\
\hline
\end{tabular}


Tabla 4. Medicamentos sin evidencia de interacciones clínicamente relevantes. Continuación

\begin{tabular}{|c|c|c|}
\hline $\begin{array}{l}\text { Grupo farmacológico o medicamentos } \\
\text { relacionados con la interacción }\end{array}$ & $\begin{array}{l}\text { Medicamento } \\
\text { VHC }\end{array}$ & Comentario \\
\hline \multicolumn{3}{|l|}{ Antiulceroso/inhibidores bomba de protones } \\
\hline Esomeprazol (29) & TLV & Interacción sin relevancia clínica \\
\hline Omeprazol $(29,33)$ & BOC/TLV & Interacción sin relevancia clínica \\
\hline Pantoprazol (33) & BOC/TLV & Interacción sin relevancia clínica \\
\hline \multicolumn{3}{|l|}{ ARV } \\
\hline Abacavir (83) & INF & Interacción sin relevancia clínica \\
\hline Darunavir (61) & SOFOSBUVIR & $\begin{array}{l}\text { El sofosbuvir no tiene afinidad ni interactúa con ningún citocromo del CYP450. No } \\
\text { convergen rutas metabólicas, interacción sin relevancia clínica. }\end{array}$ \\
\hline Dolutegravir $(39,77,78)$ & BOC/TLV & Interacción sin relevancia clínica \\
\hline Efavirenz (61) & SOFOSBUVIR & $\begin{array}{l}\text { El sofosbuvir no tiene afinidad ni interactúa con ningún citocromo del CYP450. No } \\
\text { convergen rutas metabólicas, interacción sin relevancia clínica. }\end{array}$ \\
\hline Emtricitabina $(15,38,40)$ & BOC/TLV & Interacción sin relevancia clínica \\
\hline Etravirina $(11,24,28,35,38,39)$ & TLV & Etravirina disminuye en $29 \%$ EL ABC de telaprevir, interacción sin relevancia clínica. \\
\hline Lamivudina $(38,40)$ & BOC/TLV & Interacción sin relevancia clínica \\
\hline Raltegravir (61) & SOFOSBUVIR & $\begin{array}{l}\text { El sofosbuvir no tiene afinidad ni interactúa con ningún citocromo del CYP450. No } \\
\text { convergen rutas metabólicas, interacción sin relevancia clínica. }\end{array}$ \\
\hline Raltegravir $(16,11,24,28,37,38,39,51,84)$ & $\mathrm{BOC} / \mathrm{TLV}$ & Interacción sin relevancia clínica \\
\hline Rilpivirina (61) & SOFOSBUVIR & $\begin{array}{l}\text { El sofosbuvir no tiene afinidad ni interactúa con ningún citocromo del CYP450. No } \\
\text { convergen rutas metabólicas, interacción sin relevancia clínica. }\end{array}$ \\
\hline Ritonavir $(10,11,16,19,40)$ & $\mathrm{BOC} / \mathrm{TLV}$ & Interacción sin relevancia clínica \\
\hline Tenofovir (61) & SOFOSBUVIR & $\begin{array}{l}\text { El sofosbuvir no tiene afinidad ni interactúa con ningún citocromo del CYP450. No } \\
\text { convergen rutas metabólicas, interacción sin relevancia clínica. }\end{array}$ \\
\hline $\begin{array}{l}\text { Tenofovir }(10,15,16,19,24,28,62,37,38 \\
39,42,74,84,85)\end{array}$ & $\mathrm{BOC} / \mathrm{TLV}$ & Interacción sin relevancia clínica \\
\hline \multicolumn{3}{|l|}{ Hipolipemiante/estatina } \\
\hline Fluvastatina (52) & $\mathrm{BOC} / \mathrm{TLV}$ & $\begin{array}{l}\text { Fluvastatina es metabolizado por CYP2C9. No convergen rutas metabólicas, } \\
\text { interacción sin relevancia clínica }\end{array}$ \\
\hline Pravastatina $(26,52)$ & $\mathrm{BOC}$ & $\begin{array}{l}\text { Boceprevir aumenta el ABC de pravastatina de } 0,7 \text { a } 1 \text { veces, interacción sin } \\
\text { relevancia clínica }\end{array}$ \\
\hline \multicolumn{3}{|l|}{ Inmunosupresores } \\
\hline Ciclosporina (61) & SOFOSBUVIR & $\begin{array}{l}\text { El sofosbuvir no tiene afinidad ni interactúa con ningún citocromo del CYP450. No } \\
\text { convergen rutas metabólicas, interacción sin relevancia clínica }\end{array}$ \\
\hline Tacrolimus (61) & SOFOSBUVIR & $\begin{array}{l}\text { El sofosbuvir no tiene afinidad ni interactúa con ningún citocromo del CYP450. No } \\
\text { convergen rutas metabólicas, interacción sin relevancia clínica }\end{array}$ \\
\hline \multicolumn{3}{|l|}{ Sedantes } \\
\hline Ketamina (26) & TLV & No convergen rutas metabólicas, interacción sin relevancia clínica \\
\hline
\end{tabular}

ARV: agente antiretroviral; BOC: boceprevir; INF: interferón alfa pegilado; IV: Intravenoso; RIB: ribavirina; TLV: telaprevir.

\section{DISCUSIÓN}

El VHC es una patología crónica que puede estar asociada a la coinfección con VIH y a otras enfermedades, lo que puede llevar a la necesidad terapéutica de utilizar conjuntamente ARV, medicamentos para el VHC y para otras morbilidades concomitantes, situación que aumenta la probabilidad de IM clínicamente relevantes. La presente revisión estructurada, especifica de interacciones en el tratamiento del VHC y complementada con una búsqueda sobre interacciones entre antiretrovirales y medicamentos para el tratamiento del VHC, identificó un total de 128 parejas de IM de relevancia clínica: Nivel 1: 2 (1,6\%); Nivel 2: 110 (85,9\%); Nivel 3: 16 (12,5\%) y Nivel 4: 0 (0,0\%). 
La valoración de dicha relevancia clínica se fundamenta en un método propuesto por los autores, basado en la probabilidad de ocurrencia y la gravedad de la interacción (7), lo cual es una fortaleza del presente trabajo, con respecto a otros similares (1). Además, se encontraron 78 parejas de medicamentos con evidencia de ausencia de interacción clínicamente relevante.

Similar a los hallazgos de otras revisiones estructuradas de interacciones en otro grupo de pacientes, caso de infectados con VIH (8) o con dislipidemia (80), las IM clínicamente relevantes son de mecanismo farmacocinético, en especial por la inhibición o la inducción enzimática, lo cual muestra la necesidad de que el clínico evalúe la farmacoterapia concomitante, en los casos en los que se empelan fármacos con capacidad de afectar la actividad enzimática del complejo CYP450.

En general, un inductor de la CYP genera un aumento en la actividad de la enzima y, por tanto, una disminución en los niveles plasmáticos de sus sustratos; por su parte, un inhibidor disminuye la actividad de dicha enzima $y$, con ello, un aumento de las concentraciones plasmáticas de sus sustratos. Sin embargo, el BOC y TLV no se comportan siempre de esta manera. En este sentido, en un estudio realizado en voluntarios sanos, los niveles de TLV disminuyeron cuando se administró concomitantemente con IP potenciado con ritonavir (IP/r), en lugar de aumentar sus niveles, (como era de esperarse por el efecto inhibidor fuerte del ritonavir del CYP3A4 $(81,82)$. Por ello, la importancia de realizar revisiones estructuradas orientadas a identificar artículos con resultados de estudios realizados en humanos, superando las IM teóricas, definidas por la similitud o diferencia de las vías metabólicas de los fármacos relacionados con la posible interacción, tal como se realizó en el presente trabajo.

Los antiarrítmicos, inmunosupresores, estatinas y derivados del ergot son los medicamentos con mayor frecuencia de interacciones (26 de las 128 parejas de IM relevantes) debido a la capacidad de los IP (TLV y BOC) de inhibir la CYP3A4 y la glicoproteína-P (TLV). Por su parte, INF y $\mathrm{RIB}$, debido a que se eliminan principalmente por vía renal, tienen una menor frecuencia de interacciones farmacocinéticas. También, en relación con los aspectos de seguridad, Back D y colaboradores establecieron que los grupos farmacológicos como diuréticos, inhibidores de la enzima convertidora de angiotensina y antagonistas del receptor de la angiotensina II, no se metabolizan de manera significativa por el CYP3A4, por lo que se espera que su combinación con telaprevir no genere IM (29), información respaldada con los resultados de la presente revisión. Sin embargo, solo se evidenció la ausencia de interacción con enalapril y ramipril. Similarmente, el mismo Back establecieron que los $\beta$-bloqueadores tampoco presentan problemas al usarlos con IP, debido a que se eliminan principalmente por vía renal (p. ej., atenolol y sotalol) o se metabolizan a través de CYP2D6 (p. ej., metoprolol y carvedilol) (29). En general, esta aseveración coincide con la ausencia de interacción clínicamente relevante de BOC y TLV con atenolol identificada en el presente trabajo; sin embargo, se aleja del hallazgo del aumento en los niveles plasmáticos de sotalol al combinarse con TLV. Este efecto podría deberse a que, como el sotalol es sustrato de la Glicoproteína-P (76), y el TLV inhibe dicha glicoproteína.

La presente revisión documentó información sobre la ausencia de interacciones de relevancia clínica para el sofosbuvir (61), un inhibidor de polimerasa recientemente comercializado y aprobado por la Food and drug administration. Este fármaco, al parecer no es sustrato, inhibidor e inductor de alguna isoenzima del CYP450, lo que limita la posibilidad de IM relevantes con medicamentos como tacrolimus, cilcosporina, rilpivirina y efavirenz, y sería una ventaja clínica en pacientes con VHC y otras comorbilidades. Las limitación principal de este estudio es que la búsqueda se restringió a la base de datos PubMed/Medline. Sin embargo, este efecto podría haber sido minimizado, debido a que la revisión se complementó con la búsqueda de referencias bibliográficas de IM en pacientes infectados con VIH en tratamiento antirretroviral.

\section{CONCLUSIONES}

En los pacientes infectados por el VHC que reciben terapia farmacológica, más del 90\% de las IM de relevancia clínica son farmacocinéticas, asociadas a la inducción o inhibición del metabolismo hepático. En pacientes infectados con el VHC y otras enfermedades asociadas, cuando se utilizan como antivirales el TLV o el BOC, pueden ser frecuentes las interacciones clínicamente relevantes. En este sentido, del TLV es el medicamento del que más pares de interacciones se identifican (63): 2 nivel 1 (1,6\%), 56 de nivel 2 $(43,7 \%)$ y 5 de nivel $3(3,9 \%)$. Por su parte, del BOC se identifican 54 pares de interacciones: 44 de nivel $2(34,4 \%)$ y 10 de nivel 3 (7,8\%). Por ello, en pacientes con VHC, en tratamiento con estos tres fármacos, y con otras enfermedades asociadas, puede alterar las concentraciones plasmáticas de los medicamentos concomitantes. Esta situación es más probable en los casos en los que el TLV o el BOC se usan concomitantemente con antiarrítmicos, inmunosupresores, estatinas y derivados del ergot. Por su parte, cuando se utilizan INF, RIB o sofobuvir, la probabilidad de interacciones relevantes es menor. Esta situación se debe, fundamentalmente, a que en su eliminación no participan isoenzimas del complejo CYP450. Esta característica favo- 
rece su elección para el tratamiento del VHC en pacientes que tienen otras enfermedades asociadas, especialmente infectados con el VIH o con trasplantes de órganos sólidos.

\section{Fuente de apoyo financiero}

El grupo Promoción y Prevención Farmacéutica recibió financiación de la convocatoria de sostenibilidad 2014-2015 del Comité para el Desarrollo de la Investigación (CODI) de la Universidad de Antioquia, Medellín, Colombia.

\section{REFERENCIAS}

1. Izquierdo-García E, Escobar-Rodríguez I. [Systematic review of new protease inhibitors interactions: telaprevir and boceprevir]. Farm Hosp. 2012;36:469-82.

2. Morillo Verdugo R, Romero Gómez M. [A new therapeutic scene in the treatment of the chronic hepatitis for virus $\mathrm{C}]$. Farm Hosp. 2012;36:466-8.

3. Mallolas Masferrer J, Martínez-Rebollar M, Laguno Centeno M. [Treatment of hepatitis C virus in HIV-positive patients]. Gastroenterol Hepatol. 2011;34:558-67

4. Benhamou Y, Bochet M, Di Martino V, Charlotte F, Azria F, Coutellier A, Vidaud M, Bricaire F, Opolon P, Katlama C, Poynard T. Liver fibrosis progression in human immunodeficiency virus and hepatitis $C$ virus coinfected patients. The Multivirc Group. Hepatology. 1999;30:1054-8.

5. Valencia ME, Moreno V. [Coinfection with HIV and HCV: abacavir and ribavirine, why not?]. Rev Clin Esp. 2012;212:26-30.

6. Soriano V, Martin-Carbonero L, Vispo E, Labarga P, Barreiro P. [Human immunodeficiency virus infection and viral hepatitis]. Enferm Infecc Microbiol Clin. 2011;29:691-701.

7. Amariles P, Giraldo NA, Faus MJ. Interacciones Medicamentosas: aproximación para Establecer y evaluar su relevancia clínica. Med Clin Barc 2007; 129:27-35.

8. Giraldo NA, Amariles P, Gutiérrez FJ, Monsalbe M, Faus MJ. Aproximación para establecer y evaluar la relevancia clínica de las interacciones medicamentosas en pacientes infectados con virus de la inmunodeficiencia humana: actualización 2009. Farm Hosp 2010;34:90-93

9. Bruce RD, Moody DE, Altice FL, Gourevitch MN, Friedland $\mathrm{GH}$. A review of pharmacological interactions between HIV or hepatitis $\mathrm{C}$ virus medications and opioid agonist therapy: implications and management for clinical practice. Expert Rev Clin Pharmacol. 2013;6:249-69.

10. Seden K, Back D. Directly acting antivirals for hepatitis C and antiretrovirals: potential for drug-drug interactions. Curr Opin HIV AIDS. 2011;6:514-26.

11. Rodríguez-Torres $\mathrm{M}$. Challenges in the treatment of chronic hepatitis $\mathrm{C}$ in the HIV/HCV-coinfected patient. Expert Rev Anti Infect Ther. 2012;10:1117-28.

12. Varun Garg, Gurudatt Chandorkar, Yijun Yang, Nathalie Adda,et al :The effect of CYP3A inhibitors and inducers on the pharmacokinetics of telaprevir in healthy volunteers, $\mathrm{Br}$ J Clin Pharmacol 2012;75:431-39

13. Hulskotte EG, Feng HP, Xuan F, van Zutven MG, Treitel MA, Hughes EA, O’Mara E, Youngberg SP, Wagner JA, Butterton JR. Pharmacokinetic interactions between the hepatitis $\mathrm{C}$ virus protease inhibitor boceprevir and ritonavir-boosted HIV-1 protease inhibitors atazanavir, darunavir, and lopinavir. Clin Infect Dis. 2013;56:718-26.

14. Ceballos ME. [Considerations in first line antiretroviral selection for adults]. Rev Chilena Infectol. 2013;30:522-37.

15. Kiser JJ, Burton JR, Anderson PL, Everson GT. Review and management of drug interactions with boceprevir and telaprevir. Hepatology. 2012;55:1620-8.

16. Sulkowski MS. HCV therapy in HIV-infected patients. Liver Int. 2013;33 Suppl 1:63-7.

17. Schwarze-Zander C, Rockstroh JK. HIV protease inhibitors in combination with boceprevir: are drug-drug interactions the same for all patients? AIDS. 201210;26:1845-6.

18. Tseng A, Foisy M, Hughes CA, Kelly D, Chan S, Dayneka $\mathrm{N}$, et al. Role of the Pharmacist in Caring for Patients with HIV/AIDS: Clinical Practice Guidelines. Can J Hosp Pharm. 2012;65:125-45.

19. Rodríguez-Torres M. Focus on drug interactions: the challenge of treating hepatitis $\mathrm{C}$ virus infection with directacting antiviral drugs in the HIV-positive patient. Curr Opin Infect Dis. 2013;26:50-7.

20. Deeks D. E. Darunavir: A Review of Its Use in the Management of HIV-1 Infection, Drugs (2014) 74:99-125

21. Lauren J Gleason, Amneris E Luque, Krupa Shah; Polypharmacy in the HIV-infected older adult population Clinical Interventions in Aging 2013:8 749-763

22. M. Rabanal Tornero; Terapia de sustitución con metadona: interacciones farmacológicas y no farmacológicas; Butlletí d'informació terapéutica. Generalitat de Catalunya, Departament de salut, Vol 24, num 6.2013.

23. Vanpouille C, Lisco A, Introini A, Grivel JC, Munawwar A, Merbah M, et al.Exploiting the anti-HIV-1 activity of acyclovir: suppression of primary and drug-resistant HIV isolates and potentiation of the activity by ribavirin. Antimicrob Agents Chemother. 2012;56:2604-11.

24. Mauss S, Klinker H. Drug-drug interactions in the treatment of HCV among people who inject drugs. Clin Infect Dis. 2013;57 Suppl 2:125-8.

25. Ingiliz P, Rockstroh JK. HIV-HCV co-infection facing HCV protease inhibitor licensing: implications for clinicians. Liver Int. 2012;32:1194-9.

26. Burger D, Back D, Buggisch P, Buti M, Craxí A, Foster G, et al. Clinical management of drug-drug interactions in HCV therapy: challenges and solutions. J Hepatol. 2013;58:792-800.

27. Teixeira R, Nascimento Yde A, Crespo D. Safety aspects of protease inhibitors for chronic hepatitis $\mathrm{C}$ : adverse events and drug-to-drug interactions. Braz J Infect Dis. 2013;17:194-204.

28. Kiser JJ, Burton JR Jr, Everson GT. Drug-drug interactions during antiviral therapy for chronic hepatitis C. Nat Rev Gastroenterol Hepatol. 2013;10:596-606. 
29. Berenguer BerenguerJ, González-GarcíaJ. [Pharmacokinetic interactions of telaprevir with other drugs]. Enferm Infecc Microbiol Clin. 2013;31 Suppl 3:37-48.

30. Back D, Else L. The importance of drug-drug interactions in the DAA era. Dig Liver Dis. 2013;30:45 Suppl 5:S343-8.

31. Sockalingam S, Tseng A, Giguere P, Wong D. Psychiatric treatment considerations with direct acting antivirals in hepatitis C. BMC Gastroenterol. 201314;13:86.

32. Barritt AS 4th, Fried MW. Maximizing opportunities and avoiding mistakes in triple therapy for hepatitis $\mathrm{C}$ virus. Gastroenterology. 2012;142:1314-1323.

33. Kozielewicz D, Halota W, Dybowska D. Preparation of $\mathrm{HCV}$ infected patients to the triple therapy with first generation protease inhibitors. Przegl Epidemiol. 2013;67:6238,713-6.

34. Lamers $\mathrm{MH}$, Broekman MM, Boucher CA, Brouwer JT, Burger DM, van Hoek B, Hoepelman AI, de Knegt RJ, Reesink HW, Drenth JP et al. Treatment of hepatitis C monoinfection in adults--Dutch national guidelines. Neth $\mathrm{J}$ Med. 2013;71:377-85.

35. Sulkowski MS. HCV therapy in HIV-infected patients. Liver Int. 2013;33 Suppl 1:63-7.

36. Jennings CL, Sherman KE. Hepatitis C and HIV co-infection: new drugs in practice and in the pipeline. Curr HIV/ AIDS Rep. 2012;9(3):231-7.

37. Luetkemeyer AF, Havlir DV, Currier JS. Complications of HIV disease and antiretroviral therapy. Top Antivir Med. 2012;20:48-60.

38. Puoti M, Rossotti R, Travi G, Panzeri C, Morreale M, Chiari $\mathrm{E}$, et al. Optimizing treatment in $\mathrm{HIV} / \mathrm{HCV}$ coinfection. Dig Liver Dis. 2013;45 Suppl 5:S355-62.

39. Karageorgopoulos DE, El-Sherif O, Bhagani S, Khoo SH. Drug interactions between antiretrovirals and new or emerging direct-acting antivirals in $\mathrm{HIV} /$ hepatitis $\mathrm{C}$ virus coinfection. Curr Opin Infect Dis. 2014;27:36-45.

40. Vachon ML, Dieterich DT. The HIV/HCV-coinfected patient and new treatment options. Clin Liver Dis. 2011;15:585-96.

41. Wilby KJ, Partovi N, Ford JA, Greanya E, Yoshida EM. Review of boceprevir and telaprevir for the treatment of chronic hepatitis C. Can J Gastroenterol. 2012;26:205-10.

42. Bruno R, Fagiuoli S, Sacchi P. Will direct-acting antivirals make a difference in HIV-HCV coinfected patients? Expert Rev Anti Infect Ther. 2011;9:699-701.

43. Sulkowski MS. Hepatitis C virus-human immunodeficiency virus coinfection. Liver Int. 2012;32 Suppl 1:129-34.

44. Kim JJ, Culley CM, Mohammad RA. Telaprevir: an oral protease inhibitor for hepatitis $\mathrm{C}$ virus infection. Am J Health Syst Pharm. 20121;69(1):19-33.

45. Schaefer M, Capuron L, Friebe A, Diez-Quevedo C, Robaeys G, Neri S, Foster GR, Kautz A, Forton D, Pariante CM. Hepatitis $C$ infection, antiviral treatment and mental health: a European expert consensus statement. J Hepatol. 2012;57:1379-90.
46. Chaparro M, Trapero-Marugán M, Moreno-Otero R, Gisbert JP. Azathioprine plus ribavirin treatment and pancytopenia. Aliment Pharmacol Ther. 2009;30:962-3.

47. Sockalingam S, Tseng A, Giguere P, Wong D. Psychiatric treatment considerations with direct acting antivirals in hepatitis C. BMC Gastroenterol. 2013;14;13-86.

48. Gutierrez-Valencia A, Ruiz-Valderas R, Torres-Cornejo A, Viciana P, Espinosa N, Castillo-Ferrando JR, Lopez-Cortes LF. Role of ritonavir in the drug interactions between telaprevir and ritonavir-boosted atazanavir. Clin Infect Dis. 2014;58:268-73.

49. O’Leary JG, McKenna GJ, Klintmalm GB, Davis GL. Effect of telaprevir on the pharmacokinetics of sirolimus in liver transplant recipients. Liver Transpl. 2013;19:463-5.

50. Lê MP, Gervais A, Le Beller C, Long K, Larrouy L, Papy E, $\mathrm{Mal} \mathrm{H}$, et al. Serious neuropsychiatric adverse effects in a hepatitis $\mathrm{C}$ virus/hepatitis $\mathrm{B}$ virus/HIV-coinfected patient receiving bosentan and telaprevir. J Antimicrob Chemother. 2013;68:1208-9.

51. Luetkemeyer AF, Havlir DV, Currier JS. CROI 2013: Complications of HIV disease, viral hepatitis, and antiretroviral therapy. Top Antivir Med. 2013;21:62-74.

52. Chauvin B, Drouot S, Barrail-Tran A, Taburet AM. Drugdrug interactions between HMG-CoA reductase inhibitors (statins) and antiviral protease inhibitors. Clin Pharmacokinet. 2013;52:815-31.

53. Charlton M. Telaprevir, boceprevir, cytochrome P450 and immunosuppressive agents--a potentially lethal cocktail. Hepatology. 2011;54:3-5.

54. Terrault N. Liver transplantation in the setting of chronic HCV. Best Pract Res Clin Gastroenterol. 2012;26:531-48.

55. Werner CR, Egetemeyr DP, Lauer UM, Nadalin S, Königsrainer A, Malek NP, Berg CP. Telaprevir-based triple therapy in liver transplant patients with hepatitis $C$ virus: a 12 -week pilot study providing safety and efficacy data. Liver Transpl. 2012;18:1464-70.

56. Garg V, van Heeswijk R, Lee JE, Alves K, Nadkarni P, Luo X. Effect of telaprevir on the pharmacokinetics of cyclosporine and tacrolimus. Hepatology. 2011;54:20-7.

57. Hulskotte E, Gupta S, Xuan F, van Zutven M, O’Mara E, Feng HP, Wagner J, Butterton J. Pharmacokinetic interaction between the hepatitis $\mathrm{C}$ virus protease inhibitor boceprevir and cyclosporine and tacrolimus in healthy volunteers. Hepatology. 2012;56:1622-30.

58. Gupta SK, Sellers E, Somoza E, Angles L, Kolz K, Cutler DL. The effect of multiple doses of peginterferon alfa- $2 b$ on the steady-state pharmacokinetics of methadone in patients with chronic hepatitis $\mathrm{C}$ undergoing methadone maintenance therapy. J Clin Pharmacol. 2007;47:604-12.

59. Berk SI, Litwin AH, Arnsten JH, Du E, Soloway I, Gourevitch MN. Effects of pegylated interferon alfa- $2 b$ on the pharmacokinetic and pharmacodynamic properties of methadone: a prospective, nonrandomized, crossover study in patients coinfected with hepatitis $\mathrm{C}$ and HIV receiving methadone maintenance treatment. Clin Ther. 2007;29:131-8. 
60. Neuman MG, Monteiro M, Rehm J. Drug interactions between psychoactive substances and antiretroviral therapy in individuals infected with human immunodeficiency and hepatitis viruses. Subst Use Misuse. 2006;41:1395-463.

61. Rodríguez-Torres M. Sofosbuvir (GS-7977), a pan-genotype, direct-acting antiviral for hepatitis $\mathrm{C}$ virus infection. Expert Rev Anti Infect Ther. 2013;11:1269-79.

62. Fowell AJ, Nash KL. Telaprevir: a new hope in the treatment of chronic hepatitis C? Adv Ther. 2010;27(8):512-22.

63. Seden K, Back D, Khoo S. New directly acting antivirals for hepatitis C: potential for interaction with antiretrovirals. J Antimicrob Chemother. 2010;65(6):1079-85.

64. Soriano V, Puoti M, Sulkowski M, Cargnel A, Benhamou Y, Peters M, Mauss S, Bräu N, Hatzakis A, Pol S, Rockstroh J. Care of patients coinfected with HIV and hepatitis C virus: 2007 updated recommendations from the HCV-HIV International Panel. AIDS. 2007;21:1073-89.

65. Lai AR, Tashima KT, Taylor LE. Antiretroviral medication considerations for individuals coinfected with HIV and hepatitis C virus. AIDS Patient Care STDS. 2006;20:678-92.

66. Nelson M, Lipman M. Management of advanced HIV disease in patients with tuberculosis or hepatitis co-infection. Int J Clin Pract. 2006;60:976-83.

67. Soriano V, Nuñez M, Garcia-Samaniego J, Labarga P, Simarro N, Martín-Carbonero L, Romero M, Ramos B, Barreiro P. Chronic hepatitis C in HIV-infected patients: those who more need therapy are those who respond less. Infect Disord Drug Targets. 2006;6:57-88.

68. Park JS, Saraf N, Dieterich DT. HBV plus HCV, HCV plus HIV, HBV plus HIV. Curr Gastroenterol Rep. 2006; 8:67-74.

69. Sherman KE. Treatment of hepatitis $C$ virus and human immunodeficiency virus co-infection. Clin Gastroenterol Hepatol. 2005;3:S118-21.

70. Mallolas Masferrer J, Martínez-Rebollar M, Laguno Centeno M. [Treatment of hepatitis C virus in HIV-positive patients]. Gastroenterol Hepatol. 2011;34:558-67.

71. Miró JM, Torre-Cisnero J, Moreno A, Tuset M, Quereda C, Laguno $\mathrm{M}$, et al. [GESIDA/GESITRA-SEIMC, PNS and ONT consensus document on solid organ transplant (SOT) in HIV-infected patients in Spain (March, 2005)]. Enferm Infecc Microbiol Clin. 2005;23:353-62.

72. Nogueira JB, Sena LC, Quintans Jde S, Almeida JR, França AV, Júnior LJ. Side effects of the therapy with peginterferon and ribavirin in chronic hepatitis C: a small audit. J Pharm Pract. 2012;25:85-8.

73. Simón-Talero M, Buti M, Esteban R. Severe anaemia related to oseltamivir during treatment of chronic hepatitis $\mathrm{C}$ : a new drug interaction? J Viral Hepat. 2012;19:14-7.

74. Ramanathan S, Cheng A, Mittan A, Ebrahimi R, Kearney BP. Absence of clinically relevant pharmacokinetic interaction between ribavirin and tenofovir in healthy subjects. J Clin Pharmacol. 2006;46:559-66.

75. Matthews GV, Dore GJ. HIV and hepatitis C coinfection. J Gastroenterol Hepatol. 2008;23:1000-8.
76. Bachmakov I, Werner U, Endress B, Auge D, Fromm MF. Characterization of beta-adrenoceptor antagonists as substrates and inhibitors of the drug transporter P-glycoprotein. Fundam Clin Pharmacol. 2006;20:273-82.

77. Cottrell ML, Hadzic T, Kashuba AD. Clinical pharmacokinetic, pharmacodynamic and drug-interaction profile of the integrase inhibitor dolutegravir. Clin Pharmacokinet. 2013;52:981-94

78. Shah BM, Schafer JJ, Desimone JA Jr. Dolutegravir: a new integrase strand transfer inhibitor for the treatment of HIV. Pharmacotherapy. 2014;34:506-20.

79. González-Colominas E, Solà R, Barrantes-González M, Salas E. [Prevalence of potential interactions between antiretroviral therapy and boceprevir or telaprevir in human immunodeficiency virus-hepatitis $\mathrm{C}$ virus coinfected patients]. Enferm Infecc Microbiol Clin. 2013;31:350-1.

80. Franco D, Henao Y, Monsalve M, Gutiérrez F, Hincapie J, Amariles P. [Hypolipidemic agents drug interactions: approach to establish and assess its clinical significance. Structured review]. Farm Hosp. 2013;37:539-57.

81. Kasserra C, Hughes E, Treitel M, et al. Clinical pharmacology of boceprevir: metabolism, excretion, and drugdrug interactions [abstract 118]. 18th Conference on Retroviruses and Opportunistic Infections, Feb 27-Mar 2, 2011, Boston, USA.

82. Garg V, Luo X, McNair L, et al. Low-dose ritonavir and the pharmacokinetics of the investigational HCV protease inhibitor telaprevir in healthy volunteers [abstract 629]. 18th Conference on Retroviruses and Opportunistic Infections, Feb 27-Mar 2, 2011, Boston, USA.

83. Solas C, Pambrun E, Winnock M, Salmon D, Poizot-Martin I, Dominguez S, Bani-Sadr F, Izopet J, Garraffo R, Peytavin G; ANRS CO-13 HEPAVIH Study Group. Ribavirin and abacavir drug interaction in HIV-HCV coinfected patients: fact or fiction? AIDS. 2012;26:2193-9.

84. Naggie S, Sulkowski MS. Management of patients coinfected with HCV and HIV: a close look at the role for directacting antivirals. Gastroenterology. 2012;142:1324-1334.e3

85. Wilby KJ, Greanya ED, Ford JA, Yoshida EM, Partovi N. A review of drug interactions with boceprevir and telaprevir: implications for HIV and transplant patients. Ann Hepatol. 2012;11:179-85.

86. Tuma P, Vispo E, Barreiro P, Soriano V. [Role of tenofovir in HIV and hepatitis $C$ virus coinfection]. Enferm Infecc Microbiol Clin. 2008;26 Suppl 8:31-7.

87. Sherman KE. New paradigms in the management of hepatitis C virus co-infections. Nat Clin Pract Gastroenterol Hepatol. 2007;4 Suppl 1:S10-6.

88. Ruiz-Sancho A, Soriano V. [HIV and HCV coinfection]. Enferm Infecc Microbiol Clin. 2006;24:335-45; quiz 346.

89. Dieterich DT. Hepatitis C virus and human immunodeficiency virus: clinical issues in coinfection. Am J Med. 199927;107:79S-84S. 